Ocean Sci. Discuss., 4, 41-106, 2007 www.ocean-sci-discuss.net/4/41/2007/ (C) Author(s) 2007. This work is licensed under a Creative Commons License.
OSD

4, 41-106, 2007

SSS variability from a global MLM

S. Michel et al.

\section{Sea surface salinity variability from a simplified mixed layer model of the global ocean}

S. Michel ${ }^{1,{ }^{*}}$, B. Chapron ${ }^{1}$, J. Tournadre ${ }^{1}$, and N. Reul ${ }^{1}$

${ }^{1}$ Laboratoire d'Océanographie Spatiale, IFREMER, Brest, France "now at: Proudman Oceanographic Laboratory, Liverpool, UK

Received: 13 December 2006 - Accepted: 19 December 2006 - Published: 15 January 2007 Correspondence to: S. Michel (smic@pol.ac.uk)

\section{Title Page}

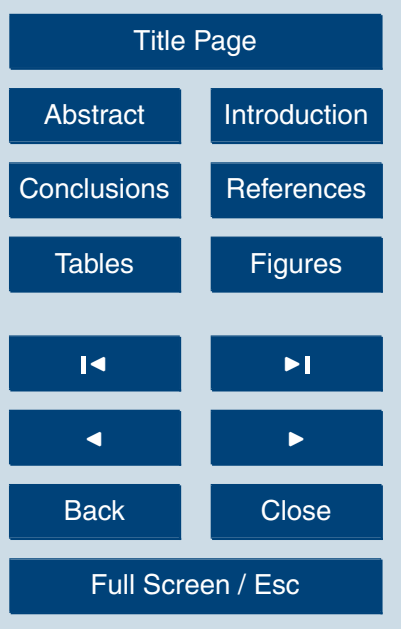

Printer-friendly Version

Interactive Discussion 


\section{Abstract}

A bi-dimensional mixed layer model (MLM) of the global ocean is used to investigate the sea surface salinity (SSS) balance and variability at daily to seasonal scales. Thus a simulation over an average year is performed with daily climatological forcing fields.

5 The forcing dataset combines air-sea fluxes from a meteorological model, geostrophic currents from satellite altimeters and in situ data for river run-offs, deep temperature and salinity. The model is based on the "slab mixed layer" formulation, which allows many simplifications in the vertical mixing representation, but requires an accurate estimate for the Mixed Layer Depth. Therefore, the model MLD is obtained from an face temperature (SST) data. The geographical distribution and seasonal variability of this "effective" MLD is validated against an in situ thermocline depth. This comparison proves the model results are consistent with observations, except at high latitudes and in some parts of the equatorial band. The salinity balance can then be analysed in all 15 the remaining areas. The annual tendency and amplitude of each of the six processes included in the model are described, whilst providing some physical explanations. A map of the dominant process shows that freshwater flux controls SSS in most tropical areas, Ekman transport in Trades regions, geostrophic advection in equatorial jets, western boundary currents and the major part of subtropical gyres, while diapycnal mixing leads over the remaining subtropical areas and at higher latitudes. At a global scale, SSS variations are primarily caused by horizontal advection (46\%), then vertical entrainment (24\%), freshwater flux (22\%) and lateral diffusion (8\%). Finally, the simulated SSS variability is compared to an in situ climatology, in terms of distribution and seasonal variability. The overall agreement is satisfying, which confirms that the salinity balance is reliable. The simulation exhibits stronger gradients and higher variability, due to its fine resolution and high frequency forcing. Moreover, the SSS variability at daily scale can be investigated from the model, revealing patterns considerably different from the seasonal cycle. Within the perspective of the future satellite missions
OSD

4, 41-106, 2007

SSS variability from a global MLM

S. Michel et al.

\section{Title Page}

Abstract Introduction

Conclusions References

Tables Figures

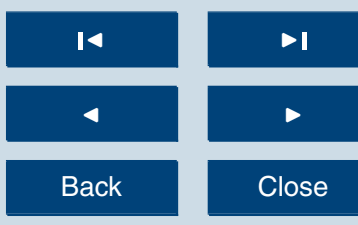

Full Screen / Esc

Printer-friendly Version

Interactive Discussion 
dedicated to SSS retrieval (SMOS and Aquarius/SAC-D), the MLM could be useful for determining calibration areas, as well as providing a first-guess estimate to inversion algorithms.

\section{Introduction}

5 The impact of sea surface salinity (SSS) on the coupled ocean/atmosphere has been recognized for a long time. Salinity in the upper layer determines the rate of deep water formation at high latitudes in winter (Dickson et al., 2002). This process modulates the intensity of thermohaline circulation, which in turn modifies the heat exchanges between tropical and polar regions, as well as between the northern and southern 10 hemispheres (Lagerloef, 2002). Thus year-to-year SSS variations are strongly linked to climate change (Boyer et al., 2005). At high latitudes, SSS is related to the sea ice melting-freezing cycle and controls the buoyancy changes. As $\mathrm{CO}_{2}$ solubility increases at low temperature, salinity variations have a strong potential for modifying the uptake of carbon from atmosphere to ocean.

15 The present knowledge of global SSS is limited by the lack of in situ measurements. Salinity data can be acquired from CTDs soundings, surface drifters, profiling floats, thermosalinographs on board of research vessels or opportunity ships, etc. But routine measurements are only available in a few limited regions. Despite constant efforts, only global climatologies can be generated, with a resolution limited to $1^{\circ}$ in space and 20 a monthly frequency. Higher resolution datasets were obtained in some well-sampled areas, using optimal data interpolation (Gaillard et al., 2005). Meanwhile, the specification of errors and correlation scales remain an open issue, as no independent method of analysis exists at the moment. At monthly scales, SSS generally exhibits an important seasonal cycle, amplified with respect to the deeper ocean. In many regions, it

aso presents a significant interannual variability, which is correlated to changes over the whole water column (Boyer et al., 2004). Nonetheless, the results from these in situ data analyses should be considered with caution. Indeed, many SSS measurements

OSD

4, 41-106, 2007

SSS variability from a global MLM

S. Michel et al.

\section{Title Page}

Abstract Introduction

Conclusions References

Tables Figures

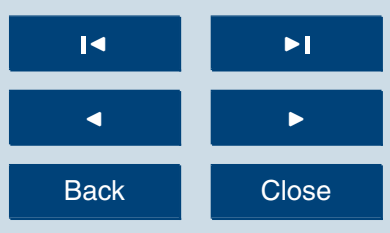

Full Screen / Esc

Printer-friendly Version

Interactive Discussion 
are performed at subsurface (at a few meters depth in the case of CTDs, profilers, etc.) and the latter can be isolated from the surface by a thin layer of fresher water.

Ocean General Circulation Models (OGCMs) represent precious tools to estimate salinity variations. For instance, they are not biased by the actual depth or the avail5 ability of data. Unfortunately, the representation of near-surface processes is still relatively poor in such models. Additionally, important inconsistencies remain in existing surface fluxes datasets, especially in the freshwater component. Thus, these models often require some kind of relaxation towards a SSS climatology, to prevent strong drift during long simulations (Paiva and Chassignet, 2000). More sophisticated techniques 10 rely on the assimilation of salinity, where data are not too sparse in time and space. But assimilation methods generally produce shocks at the beginning of each cycle and no precise long-term budgets can be inferred from that kind of models. Moreover, as in the case of optimal interpolations, the estimation of uncertainties (for the error covariance matrix) is still an unsolved problem for salinity.

15 A variety of mixed layer models (MLMs) has been developed to improve the representation of the upper ocean processes. They range from intermediary complexity 3-D models (Alexander et al., 2000), to 2-D horizontal (Qiu and Kelly, 1993) and 1D vertical models (Caniaux et al., 2005b). Such models have been used mainly to study the mixed layer temperature, because it has a direct impact on the air-sea heat exchanges and a generally higher impact on the circulation through geostrophic currents. The SST and thermal profile are then quite well reconstructed in these models, but salinity suffers from larger uncertainties.

In this study, we present a 2-D mixed layer dedicated to the SSS retrieval, making use of state-of-the-art surface and subsurface datasets. The model is based on the classical "slab mixed layer" formulation (Frankignoul and Hasselmann, 1977), consisting in a vertically integrated mixed layer above a passive deep layer. An inversion method is proposed to compute a mixed layer depth (MLD) which is intrinsically consistent with the model formulation and forcing. The model is forced continuously by wind-induced and geostrophic currents. This technique does not require a spin-up and does not gen-

OSD

4, 41-106, 2007

SSS variability from a global MLM

S. Michel et al.

\section{Title Page}

Abstract Introduction

Conclusions References

Tables Figures

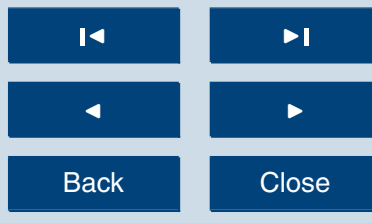

Full Screen / Esc

Printer-friendly Version

Interactive Discussion

EGU 
erate shocks, allowing for long-term budget estimation. The model simplicity enables fast computations. Thus global simulations are affordable (avoiding the delicate setting of open boundaries conditions) and they can be integrated for several years (allowing the assessment of long-term variability).

5 This study focuses on the SSS variability over the global ocean, at a rather fine scale ( $1^{\circ}$ in both directions) and at time scales spanning from days to years. The model takes advantage of the high quality surface data which are currently available at these scales, from remote sensing measurements and meteorological model outputs. The simulation results are analysed to address some of the key issues on the role of surface 10 salinity:

- Which processes dominate the local salt budget?

- What is the relative importance of surface forcing and deep processes?

- Which are the critical input parameters to simulate realistic salinity variations?

- Where are the highest and lowest SSS variability areas?

- What is the annual evolution of SSS in poorly sampled areas?

- How does daily variations in salinity compare to its seasonal cycle?

In the next section, we briefly describe the model formulation, its global implementation and the forcing datasets. In the third section, we present an inversion technique to deduce the MLD from observed SST variations then we validate the results against in situ data. In the fourth section, we analyse the mixed layer salinity balance obtained using a climatological forcing. In the fifth section, the daily-to-seasonal SSS variability is addressed and compared to in situ measurements. In the last section, the model results are summarized, future improvements are described and some possible applications are discussed.

\section{OSD}

4, 41-106, 2007

SSS variability from a global MLM

S. Michel et al.

\section{Title Page}

Abstract Introduction

Conclusions References

Tables

Figures

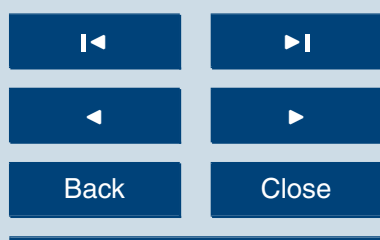

Full Screen / Esc

Printer-friendly Version

Interactive Discussion 


\section{Model design}

The model is based on the slab mixed layer formulation, which was originally developed to analyse atmosphere/ocean interactions under a stochastic forcing (Frankignoul and Hasselmann, 1977). This formulation has also been used to investigate the upper 5 layer salinity variability at interannual to decadal scales, in a coupled GCM of the North Atlantic (Mignot and Frankignoul, 2003). The same concept has been exploited to simulate the mixed layer evolution in the Kuroshio extension region (Qiu and Kelly, 1993).

\subsection{Slab mixed layer formulation}

10 The mixed layer is represented as a slab of seawater (Fig. 1), having uniform properties from its top (the air-sea interface) to its bottom. The temperature $T$ and salinity $S$ of this layer are supposed to be equal to the SST and SSS, respectively. Alternatively, $T$ and $S$ can be considered as vertically averaged quantities over the layer thickness. The equations governing $T$ and $S$ evolutions are based on the heat and salt conservation 15 in the mixed layer and can be written as follows:

$\frac{\partial T}{\partial t}=\frac{Q_{\text {net }}}{C_{p} \rho_{0} h}-\boldsymbol{u} \cdot \nabla T-\Gamma\left(w_{e}\right) \frac{w_{e}\left(T-T_{d}\right)}{h}+k \nabla^{2} T$

$\frac{\partial S}{\partial t}=\frac{(E-P-R) S}{h}-\boldsymbol{u} \cdot \nabla S-\Gamma\left(w_{e}\right) \frac{w_{e}\left(S-S_{d}\right)}{h}+\kappa \nabla^{2} S$

where $\boldsymbol{u}$ is the (vertically averaged) current vector, $h$ is the mixed layer depth (estimated using an inversion technique, Appendix B), $T_{d}$ and $S_{d}$ are the properties of the deep layer just below $h$ and $w_{e}$ is the vertical entrainment rate at depth $z=h$. The constant parameters are the horizontal diffusivity $\kappa$, (set to a value appropriate to the resolution, Sect. 2.3) the seawater thermal capacity $C_{p}=4200 \mathrm{~J} \cdot \mathrm{kg}^{-1} \cdot \mathrm{K}^{-1}$ and the seawater reference density $\rho_{0}=1020 \mathrm{~kg} \cdot \mathrm{m}^{-3}$.

\section{OSD}

4, 41-106, 2007

SSS variability from a global MLM

S. Michel et al.

\section{Title Page}

\section{Abstract} Introduction

Conclusions References

Tables Figures

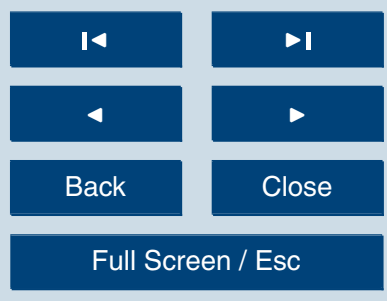

Printer-friendly Version

Interactive Discussion 
The surface fluxes are represented by the net fluxes of heat $Q_{\text {net }}$ and freshwater $E-P-R$. The net heat flux is obtained by summing the net radiative fluxes (solar shortwave radiation and thermal long-wave radiation) and the turbulent fluxes (latent heat and sensible heat). In the real ocean, a fraction of solar radiation penetrates below the 5 mixed layer. This quantity is neglected in the model, because it decreases rapidly with $h$ and is generally one order of magnitude lower than the incoming radiation. The net freshwater flux is composed of the evaporation rate $E$ (proportional to the latent heat flux), the precipitations rate $P$ and the input by river runoffs $R$. Unlike temperature, the impact of this flux on the surface water strongly depends on salinity itself. Moreover, 10 SSS has no direct feedback on the surface flux. These particularities have important consequences on the salt budget and on the duration of SSS anomalies (see Sect. 4.3).

The horizontal advection is classically separated into a wind induced component, the Ekman transport, and an internal force component, the geostrophic current:

$\boldsymbol{u}=\boldsymbol{u}_{E}+\boldsymbol{u}_{g}=\frac{1}{\rho f h} \tau \times k+\frac{g}{f} \nabla \eta \times k$

15 where $g=9.81 \mathrm{~m} \cdot \mathrm{s}^{-2}$ is the gravity acceleration, $f$ is the Coriolis frequency (in $\mathrm{s}^{-1}$, increasing with latitude), $\tau$ is the wind stress (in N.m ${ }^{-2}$ ) and $\eta$ is the sea surface elevation (in $\mathrm{m}$ ).

Ekman transport is due to wind friction on the sea surface, which is rotated by the Coriolis force as it penetrates in depth. The Ekman layer depth is systematically lower 20 than the mixed layer depth, because both increase with the wind stress, but the mixed layer is also deepened by other processes. Thus, the Ekman transport lies entirely above h. Geostrophic currents are generated by the horizontal pressure gradient, due to the atmospheric pressure field and to the density structure. This internal process is distributed over the whole water column, but density gradients are much stronger 25 close to the surface. Therefore, geostrophic adjustment occurs principally within the mixed layer and geostrophic circulation can be considered to be restricted to this layer. Moreover, as density is supposed to be uniform from the surface to the mixed layer base, the velocities are assumed to be vertically homogenous in the layer.
OSD

4, 41-106, 2007

SSS variability from a global MLM

S. Michel et al.

Title Page

Abstract Introduction

Conclusions References

Tables Figures

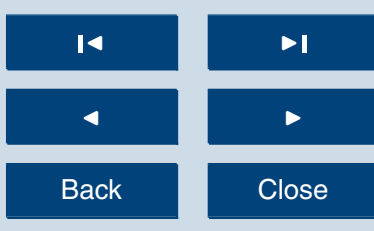

Full Screen / Esc

Printer-friendly Version

Interactive Discussion 
The vertical processes are conveniently represented by a single entrainment term, consisting in vertical Ekman advection and MLD tendency:

$w_{e}=w_{E}+w_{m}=\frac{1}{\rho}\left|\frac{\boldsymbol{\nabla} \wedge \boldsymbol{\tau}}{f}\right|+\partial_{t} h$

The Ekman vertical velocity $w_{E}$ corresponds to the upwelling (or downwelling) gener5 ated by the convergence (respectively, divergence) of the horizontal Ekman transport. The time variations of $h$, or its equivalent mixing velocity $w_{m}$, can be induced by a variety of processes, ranging from turbulent mixing (due to wind stress, current shear, internal wave breaking, etc.) to lateral induction (occurring when intermediate water is advected across the upper isopycnal interface). Thus, this term integrates the effects of several small scale mechanisms whose parameterisations are still a matter of debate, avoiding the use of any empirical parameter. It will be further referred as "diapycnal mixing", even if it can include other processes. The total entrainment term must be treated differently in case of upward or downward entrainment, so it is multiplied by a step function $\Gamma$ in Eqs. (1) and (2). Indeed, when additional water is included into the $w_{e}>0$. On the contrary, if water is removed from the mixed layer, the properties of the remaining water are conserved and only its depth $h$ can change: $\Gamma\left(w_{e}\right)=0$ if $w_{e}<0$.

The subgrid scale lateral processes are parameterized using a Laplacian horizontal diffusion, with a coefficient $k$. This term is necessary because the model is run with a relatively coarse resolution, so mesoscale and submesoscale eddy advection can not be represented explicitly, although they may have a large impact on the surface properties distribution (Giordani et al., 2005b). It was shown that $k$ should increase primarily with the eddy kinetic energy (Herterich and Hasselmann, 1987) and should depend, at second order, on other parameters such as stratification, current shear, wave height,
OSD

4, 41-106, 2007

SSS variability from a global MLM

S. Michel et al.

\section{Title Page}

Abstract Introduction

Conclusions References

Tables Figures

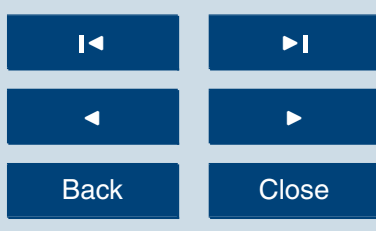

Full Screen / Esc

Printer-friendly Version

Interactive Discussion diffusivity $k$ is fixed to a lower bound value (see Sect. 2.3). 
Several restrictions must be highlighted when using such a simplified model. First of all, no equation is necessary for the dynamic part of the model, as the horizontal and vertical velocities are considered as forcing variables for the mass field. Thus, the 5 mixed layer temperature and salinity can not feedback on the model currents. This is a reasonable approximation for the wind-induced component, but is arguable for the geostrophic component. Indeed, any perturbation of the density field induces current anomalies, through the thermal wind balance. However, at large space scales (about $100 \mathrm{~km}$, much greater than the first Rossby deformation radius) the geostrophic bal-

ance is generally achieved. Additionally, at time scales from hours to days, the mass field adjust rapidly to the currents (Giordani et al., 2005a). In order to minimize the potential impact of inconsistencies between the geostrophic circulation and the mass field, the model is run using a rather low resolution and with the highest frequency from available velocity estimates (a few days).

15 Another important characteristic of the model formulation is that it does not require a turbulent closure equation. In most areas of the real ocean, turbulent processes (eddy diffusion, winter convection, mixing induced by current shear, internal waves and wind friction, etc.) strongly constrain the mixed layer evolution. In the model, these processes are represented implicitly by the "diapycnal mixing" term. Their impact on the mixed layer properties is accounted for by multiplying the variation of $h$ by the vertical gradient of $T$ or $S$ in Eqs. (1), (2) and (4). This simple paramerization avoids detailed representations of each vertical mixing process, but requires knowing the evolution of MLD.

In this model, $T$ and $S$ stand for vertically averaged quantities over the mixed layer 25 thickness, not for surface quantities. By definition, variations in thermohaline properties within the mixed layer are supposed to be small. Many authors delineate the mixed layer using a variation around $0.5^{\circ} \mathrm{C}$ in temperature or $0.02 \mathrm{~kg} \cdot \mathrm{m}^{-3}$ in density (for a review, see De Boyer-Montégut et al., 2004). Nevertheless, as the upper layer is never
OSD

4, 41-106, 2007

SSS variability from a global MLM

S. Michel et al.

\section{Title Page}

Abstract Introduction

Conclusions References

Tables Figures

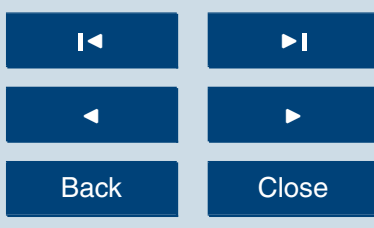

Full Screen / Esc

Printer-friendly Version

Interactive Discussion 
totally homogenous, $T$ and $S$ can not be strictly considered equal to the SST and SSS. Note that the surface properties could be reconstructed subsequently from the model outputs, using estimates for their vertical structures (such as the empirical profiles proposed by Kitaigorodski, 1973, or climatological profiles from in situ data). Similarly, 5 geostrophic velocities are assumed to be vertically uniform in the mixed layer, but the current shear could be approximated using empirical profiles.

As proposed, the simulations rely on the availability of surface elevation or geostrophic velocity data. Estimates of dynamic topography can be obtained either from an in situ climatology, a full ocean circulation model or altimetry measurements.

10 The latter solution has been chosen for our simulations, to take advantage of an accurate analysis of satellite altimetric data with high space and time resolution is now available (Appendix A). The simulation realism is also highly dependent on the consistency of momentum, heat and freshwater fluxes. In particular, fluctuations in the turbulent heat fluxes and in the evaporation must be synchronous and commensurate 15 with the fluctuations in the wind speed. Otherwise, adverse effects on the $T$ and $S$ in the surface layer could lead to spurious anomalies, which would be amplified instead of being reduced by air-sea exchanges. All the air-sea fluxes are derived from the same meteorological model, so they are consistent with each other. This model also provides the SST fields which are required to initialize the simulation and compute the MLD (Appendix B).

Finally, the model is suited for open ocean areas, but would require some modifications to be extended to coastal regions. The processes dominating the mixed layer evolution in shallow seas are characterized by much smaller temporal and spatial scales (Holt and James, 2001). In such areas, narrow currents, small eddies, bottom friction and tidal mixing have impacts similar to (if not higher than) large scale processes. Thus, the geostrophic equilibrium is rarely achieved in shallow seas and geostrophic velocities can not be used as a forcing. Moreover, the mixed layer strongly interacts with the bottom frictional layer and can even merge with it during entrainment periods. The model relies on the existence of thicker layer below the mixed layer, which is sup-

OSD

4, 41-106, 2007

SSS variability from a global MLM

S. Michel et al.

\section{Title Page}

Abstract Introduction

Conclusions References

Tables Figures

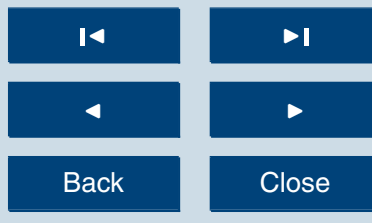

Full Screen / Esc

Printer-friendly Version

Interactive Discussion 
posed to be insensitive to rapid fluctuations at the sea surface. As a consequence, the mechanisms represented in the model may not be sufficient to simulate the complicated dynamics of continental shelves. The results obtained close to the coasts are certainly less reliable than in the deep ocean, so they must be regarded with caution.

\section{$5 \quad 2.3$ Global implementation}

The slab mixed layer model has been implemented over the global ocean. The horizontal mesh is the same as the meteorological model providing most of the forcing. The grid is isotropic, with a resolution of $1.125^{\circ}$, corresponding to mesh widths ranging from $125 \mathrm{~km}$ at the equator to $22 \mathrm{~km}$ at the highest latitudes. The domain extends between $80^{\circ} \mathrm{N}$ and $80^{\circ} \mathrm{S}$, because no altimetry data are available at higher latitudes. As the geostrophic equilibrium is not guaranteed in shallow areas, geostrophic velocities are masked at points where the depth is lower than $200 \mathrm{~m}$ (generally one grid point from the coast, except over wide continental shelf regions). Because the Coriolis force diverges at low latitudes, the Ekman terms are masked in the $3^{\circ} \mathrm{S}-3^{\circ} \mathrm{N}$ equatorial 15 band.

The advection terms are computed using a centred scheme on an Arakawa C-grid. The current velocities $(u, v)$ are interpolated at each side of a grid cell, while $T$ and $S$ are defined at the centre of each cell. Thus, the small scale thermohaline gradients are preserved (down to the width of the mesh elements), while the currents are weakly affected by the spatial interpolation because of their larger typical scales. The timestepping depends on the variable. The MLD computation is based on a semi-implicit scheme and does not require any stability criterion, so the time-step for $h$ is equal to the forcing data frequency, i.e. 1 day and approximately $100 \mathrm{~km}$. On the contrary, the simulation of $T$ and $S$ is based on a forward implicit scheme and must satisfy the CFL
OSD

4, 41-106, 2007

SSS variability from a global MLM

S. Michel et al.

\section{Title Page}

Abstract Introduction

Conclusions References

Tables Figures

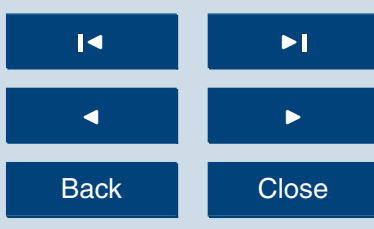

Full Screen / Esc

Printer-friendly Version

Interactive Discussion and the minimum spacing of the horizontal grid is $20 \mathrm{~km}$, thus a 1-hour time-step is sufficient to ensure numerical stability.

The coefficient $k$ for the lateral diffusion term is set according to the horizontal reso- 
lution. Many OGCMs with similar resolution use background diffusivity values around $2000 \mathrm{~m} . \mathrm{s}^{-2}$. Meanwhile, several authors have argued that $k$ should increase with the Eddy Kinetic Energy, thus reaching much higher values in strongly turbulent areas (Le Cann et al., 2005). Our model results demonstrate that horizontal diffusion term is al5 ways one or two orders of magnitude lower than the dominant processes. Thus, the diffusivity was fixed to $k=2000 \mathrm{~m} . \mathrm{s}^{-2}$, corresponding to a rather low but reasonable estimate.

The equation-of-state, used to calculate the seawater density $\rho$ from $T$ and $S$, is based on Jackett and McDougall's (1994) formulation. The mixed layer density partly

10 determines the intensity of the Ekman terms, as seen in Eqs. (3) and (4). It is also used to detect unstable stratification situations (when $\rho(z=0)>\rho(z=h)$ ), in which case the mixed layer properties are instantaneously mixed with the lower level of the climatological fields, until a stable situation is found. In particular, this algorithm provides a simple representation of deep convection occurring in winter at subpolar latitudes.

The model is run with a high-frequency climatological forcing, in order to focus on the variability at daily to seasonal scales. The air-sea fluxes and SST are extracted from the ERA40 reanalysis of ECMWF meteorological model, while the geostrophic currents are obtained from the SSALTO-DUACS analysis of altimeter dynamic topography. As these two datasets span over separated time periods (Table 1), average annual timeseries have been computed for each input variable. Moreover, deep temperature and salinity data are taken from an in situ climatology (World Ocean Atlas 2001), as well as the river run-offs data (Dai and Trenberth, 2002). The initial characteristics of the input variables are listed in Table 1 and the forcing fields preparation is detailed in Appendix A.

\section{Mixed layer depth estimate}

Various definitions for the MLD are equally pertinent, as several types of mixed layer can exist simultaneously (Fig. 2). The "mixing layer" is the layer which is affected by

OSD

4, 41-106, 2007

SSS variability from a global MLM

S. Michel et al.

\section{Title Page}

Abstract Introduction

Conclusions References

Tables Figures

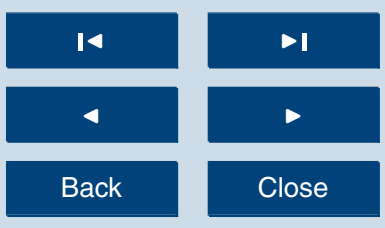

Full Screen / Esc

Printer-friendly Version

Interactive Discussion 
turbulence generated at surface, in particular through wind friction, inertial motions and wave breaking (Phillips, 1969). The "diurnal mixed layer" develops in areas with highly stable stratification, due to solar heating, then vanishes during night time (Kudryavtsev, 1990). The "seasonal mixed layer" appears as a thin layer during summer, because of 5 heat gain from the atmosphere and relatively low turbulence, then gradually deepens under cooling conditions during fall (Kitaigorodskii, 1973). In winter, it can reach the "permanent mixed layer", which in marked by a strong increase in stratification which remains all year long at approximately constant depth. In our model, the depth of the mixed layer represents the water column which is directly affected by surface fluxes, 10 at time-scales ranging from one day to the annual cycle. Thus, the most appropriate definition is the seasonal mixed layer and this estimate will be used to validate the simulated MLD.

MLD is difficult to define at a global scale and is highly dependent on the available parameters and their sampling. In situ MLD products may be highly suitable for quanti15 tative studies (for a review, see De Boyer-Montégut et al., 2004), but they are probably not consistent with the model formulation. Thus we decided not to use any in situ MLD data and to derive an estimate from the model itself. Over the global ocean, SST observations benefit of a high resolution and accuracy, especially if they are obtained from space-borne measurements. Therefore, SST data are used to obtain a specific MLD estimate, which is in agreement with the model physics and the whole forcing dataset, without relying on a subjective criterion. The technique we designed for this purpose is detailed in Appendix B.

\subsection{Horizontal variability}

The spatial distribution of MLD obtained from our inversion technique is illustrated us25 ing monthly averages for March and September, corresponding to both extremes of the seasonal cycle at subtropical to polar latitudes. The inverted MLD is validated against the "T02" thermocline depth from De Boyer-Montégut et al. (2004). This comparison is essentially qualitative, as the in situ depth is computed using a subjective criterion

\section{OSD}

4, 41-106, 2007

SSS variability from a global MLM

S. Michel et al.

\section{Title Page}

Abstract Introduction

Conclusions References

Tables Figures

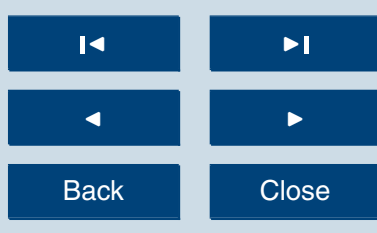

Full Screen / Esc

Printer-friendly Version

Interactive Discussion 
$\left(\mathrm{T}(\mathrm{h})-\mathrm{T}(10 \mathrm{~m})=0.2^{\circ} \mathrm{C}\right)$, while the model depth is inherent to the slab mixed layer formulation. These two MLD estimates are characterized by the same order of magnitude, but their amplitudes can be significantly different (thus, the scales differ by a factor two in Figs. 3 and 4).

In March, the in situ depth (Fig. 3a) exhibits maximum values (above $800 \mathrm{~m}$ ) in the Labrador Sea, Irminger Sea and Norway Sea, as well as between Iceland and Scotland, where deep waters are produced through convection. The model (Fig. 3b) broadly reproduces this structure with four key areas of deep convection, the northern one being slightly more extended. The MLD values reach $1000 \mathrm{~m}$ over these areas and even exceed $1500 \mathrm{~m}$ at the centre of the most convective regions. In the Pacific, the observed depth is considerably lower than in the Atlantic at the same latitudes, because the atmospheric forcing is weaker and convection occurs only marginally. The simulation does not exhibit such a high contrast, as MLD also exceeds $1000 \mathrm{~m}$ in the Pacific around $50^{\circ} \mathrm{N}$. Both the observed and simulated depths show a relatively narrow band of thicker mixed layer along the path of the Gulf Stream and North Atlantic Drift, as well as in the Kurushio and its extension (with values up to $200 \mathrm{~m}$ in the observations and $400 \mathrm{~m}$ in the simulation). The model also reproduces the areas of enhanced depth along the Trades winds, off the coasts of North-West Africa in the Atlantic and around $30^{\circ} \mathrm{N}$ in the eastern Pacific (approximately $75 \mathrm{~m}$ ). Along the equatorial band, the simulation exhibits a MLD minimum, as in the observations, except over the Warm Pool in the western and central Pacific. In this area, the local maximum in the simulated MLD is probably related to inconsistencies between the strong geostrophic currents and the atmospheric forcing.

In the southern hemisphere, the MLD is slightly increased by the South-Easterlies 25 winds, for instance in the Eastern Indian Ocean. In the AntArctic Circumpolar Current (AACC), the mixed layer is deeper because of intense wind stress, strong current shear and weak buoyancy, particularly around $110^{\circ} \mathrm{W}$ and $70^{\circ} \mathrm{E}$. The in situ estimate does not exceed $150 \mathrm{~m}$ and presents zonally elongated structures, while the model estimate contains much higher values and many small scale features. These differences

OSD

4, 41-106, 2007

SSS variability from a global MLM

S. Michel et al.

\section{Title Page}

Abstract Introduction

Conclusions References

Tables Figures

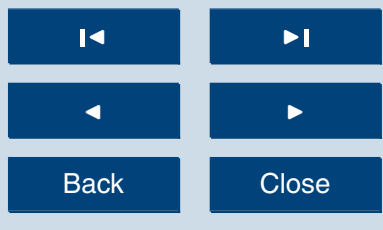

Full Screen / Esc

Printer-friendly Version

Interactive Discussion 
may arise from inconsistencies between SST data, air-sea fluxes and geostrophic circulation, all of which are less accurate at high latitudes. Additionally, the subduction process (advection of water across the mixed layer base, associated to strong currents and weak stratification) is not explicitly included in the model and could be of criti5 cal importance within the AACC. Moreover, as in situ measurements are particularly rare over southern subpolar regions, the thermocline depth estimate should also be regarded with caution.

September averages reveal a very different picture of the mixed layer horizontal distribution. The in situ depth (Fig. 4a) exhibits almost constant values over the whole 10 northern hemisphere (less than $40 \mathrm{~m}$ ), apart from a patch in the Atlantic, to the South of Iceland $(50 \mathrm{~m})$. The simulated MLD (Fig. $4 \mathrm{~b}$ ) is seemingly uniform, except in western boundary currents, possibly because of divergences in the geostrophic currents. In tropical regions, the observed MLD is enhanced below the ITCZs (up to $100 \mathrm{~m}$ ), especially in the eastern Pacific and in the central Indian Ocean, due to the monsoon 15 system. In the simulation, the mixed layer presents similar tropical structures, but the maxima are located closer to the coasts of Southern America and Eastern Africa. In the southern hemisphere, the MLD is enhanced over Trades winds regions, in the eastern part of the Pacific and Atlantic oceans (reaching 150 and $125 \mathrm{~m}$, respectively). The subtropical maxima lie within the subtropical gyres in the observations, while they are situated closer to the continents in the simulation. At subpolar latitudes, the deep mixed layer associated to the AACC exhibits a much greater extension than in summer. In the observations, two zonally stretched areas present depths higher than $300 \mathrm{~m}$, from $150^{\circ} \mathrm{W}$ to Cape Horn and from $70^{\circ} \mathrm{E}$ to the South of Australia. The simulation depicts a wider and more elongated structure, covering all longitudes, with values as high as $25500 \mathrm{~m}$ locally.

\subsection{Seasonal variability}

The simulated MLD variability is compared to the in situ climatology, in terms of standard deviation of the monthly fields. These two estimates should not be compared
OSD

4, 41-106, 2007

SSS variability from a global MLM

S. Michel et al.

\section{Title Page}

Abstract Introduction

Conclusions References

Tables Figures

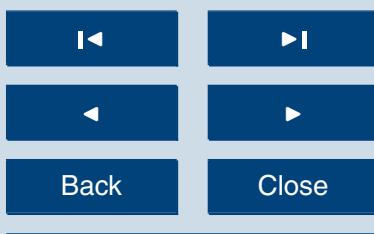

Full Screen / Esc

Printer-friendly Version

Interactive Discussion 
quantitatively, as each depth is based on a different definition of the mixed layer. Therefore, in the simulation the maximum variance is greater by a factor four with respect to the climatology (Fig. 5). The observed variability reaches $150 \mathrm{~m}$ in the Weddell Sea, while the simulated variability reaches almost $500 \mathrm{~m}$ in the Labrador Sea and $400 \mathrm{~m}$ 5 in the subpolar North Pacific. In the climatology, the maximum variability in the North Pacific (about $50 \mathrm{~m}$ ) is half lower than in the North Atlantic (reaching $100 \mathrm{~m}$ ). The simulated field also exhibits local maxima in these areas, associated to deep water formation during winter, but the values are similar in both oceans. Therefore, the maximum in the North Pacific seems overestimated, due to the very high depths obtained in March 10 (see Fig. 3b). Other maxima are found in the northern parts of the Gulf Stream and the Kuroshio, while the observations show wider maxima which extend slightly farther South. As stated previously, this discrepancy is probably caused by strong divergences in the geostrophic velocities.

MLD exhibits its lowest variability in tropical regions, particularly in the eastern 15 basins, due to quasi permanent winds and heat forcing, as well as weak surface currents. In these areas, both the observation and the simulation present very low standard deviations, of order $10 \mathrm{~m}$ and $20 \mathrm{~m}$, respectively. In the simulation, the low values spread from the equator to $30^{\circ}$ in each hemisphere, whereas in the observations they are confined between $15^{\circ} \mathrm{S}$ and $15^{\circ} \mathrm{N}$. At southern subpolar latitudes, the mixed layer is much more variable, due to winter deepening. The observed variability reaches $100 \mathrm{~m}$ in the AACC, upstream from Cape Horn (around $90^{\circ} \mathrm{W}$ ) and to the South-West of Australia (between $80^{\circ} \mathrm{E}$ and $130^{\circ} \mathrm{E}$ ). The simulation also exhibits increased variability in these areas (about $300 \mathrm{~m}$ ), but the maximum values are found at the longitudes of the Atlantic and eastern Indian Ocean (between $30^{\circ} \mathrm{W}$ and $110^{\circ} \mathrm{E}$ ). The variance maxi25 mum lies within the core of the AACC in the simulation (along $60^{\circ} \mathrm{S}$ ), while it is located at the subpolar front stream in the observations (around $55^{\circ} \mathrm{S}$ in the eastern Pacific and $50^{\circ} \mathrm{S}$ in the Indian Ocean). This model deficiency is related to an overestimation of the deepening under extreme surface cooling, in presence of strong currents and low thermal stratification. Nonetheless, as in situ measurements are extremely sparse
OSD

4, 41-106, 2007

SSS variability from a global MLM

S. Michel et al.

\section{Title Page}

Abstract Introduction

Conclusions References

Tables Figures

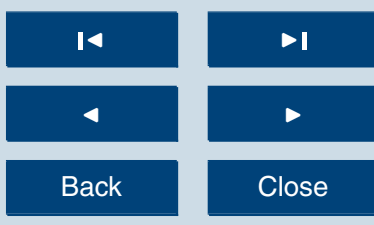

Full Screen / Esc

Printer-friendly Version

Interactive Discussion 
at high southern latitudes, the climatology is less reliable in this region.

The phase of the seasonal evolution of the MLD is validated through its time correlation with in situ estimates. The monthly correlation between the "T02" thermocline depth and the simulated MLD (Fig. 6) is satisfying over most of the global ocean. The 5 correlation values are typically higher than 0.8 and even greater than 0.9 at midlatitudes, particularly in the North Atlantic and North-East Pacific. Despite this overall agreement, the correlation is very low in tropical areas, essentially below ITCZs (around $5^{\circ} \mathrm{S}$ and $10^{\circ} \mathrm{N}$ ). This defect could imply that the model lacks some mixing mechanism which is particularly important at low latitudes. But it could also indicate 10 that the surface heat flux is not consistent with the SST evolution. Indeed, the ECMWF model, like many weather prediction systems, does not simulate correcly the cloud cover and the evaporation in convective regions, resulting in large errors in the solar and latent heat fluxes. Moreover, the correlation between the observed depths of T02 thermocline and R003 pycnocline (based on $\rho(10 \mathrm{~m})-\rho(h)=0.03 \mathrm{~kg} \cdot \mathrm{m}^{-3}$ ) are close to 15 zero in many tropical areas (not shown). Therefore, the low correlations could also be associated to hydrological contexts where the thermocline is not representative of the effective mixed layer boundary (in cases of "salt barrier" or "compensated layer").

The correlation is rather low in the Gulf Stream and Kuroshio, because the model is not adapted to intense geostrophic currents and strong divergence. At subpolar latitudes, the correlation is generally negative in regions covered with sea ice during part of the year. In case of ice formation (SST lower than $-1.8^{\circ} \mathrm{C}$ ), the model MLD is kept to its previous value (corresponding to a fall maximum), until the surface becomes ice free (during spring). On the contrary, the in situ depth can be computed despite the presence of sea ice, using subsurface measurements. SST generally becomes lower than temperature at depth, leading to the formation of a thin winter thermocline. Thus the model MLD is kept to a maximum in winter, while the in situ depth reaches a minimum, which explains the negative correlations obtained in polar regions.
OSD

4, 41-106, 2007

SSS variability from a global MLM

S. Michel et al.

\section{Title Page}

Abstract Introduction

Conclusions References

Tables Figures

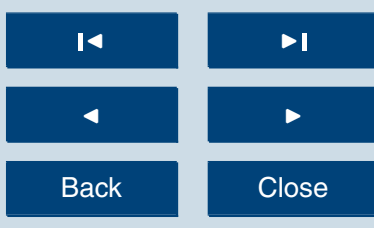

Full Screen / Esc

Printer-friendly Version

Interactive Discussion 


\subsection{Mixed layer stability}

The stability of our MLD inversion algorithm is assessed from the annual drift, computed as the difference between the end and beginning of the climatological simulation (31 December minus 1 January). The December-January period corresponds to a 5 rather slow deepening at northern midlatitudes and a sustained shallow mixed layer at southern midlatitudes. Thus, this drift estimate shall be relatively insensitive to chosen date. The annual drift of MLD (Fig. 7) is generally lower than \pm 10 m.year $^{-1}$, proving that its seasonal evolution is self-consistent over most of the global domain.

In the inter-tropical band, the mixed layer deepens by about $-10 \mathrm{~m} /$ year in some 10 small areas. The surface fluxes from the meteorological model are less accurate over the ITCZs (see Sect. 3.2) and the thin mixed layer is more sensitive to the fluxes errors. Moreover, the presence of salt barrier layers can alter the link between the observed SST and the simulated MLD. Thus haline stratification would result in a lower MLD than in regions where the stratification is controlled by temperature alone.

15 At midlatitudes, the MLD drift appears quite noisy, but no clear tendency appears at large scale, thus the simulated depth is fairly stable. Nonetheless, large scale tendencies are obtained in the eastern Pacific, with values reaching $-5 \mathrm{~m}_{\text {.year }}^{-1}$ around $40^{\circ} \mathrm{N}$ and +5 m.year $^{-1}$ around $30^{\circ} \mathrm{S}$. In these areas, the model is not able to find an exact balance between entrainment and detrainment, possibly because of inconsistencies within the atmospheric forcing.

At subpolar latitudes, the MLD drift reaches considerably higher values, as high as \pm 100 m.year $^{-1}$ locally. In the central Labrador Sea, the mixed layer deepens by about $+100 \mathrm{~m}$, while in the Arctic Ocean the MLD decreases by approximately the same amount. Such regions are characterized by very intense convection during winter, 25 so the drift estimate is more sensitive to the reference date than elsewhere. In the Antarctic Ocean, the drift values exhibit the same order of magnitude, but its distribution is burdened with small features all along the AACC. The large scale tendency indicates a deepening of the mixed layer, pointing to model inadequacy to the local physics. This
OSD

4, 41-106, 2007

SSS variability from a global MLM

S. Michel et al.

\section{Title Page}

Abstract Introduction

Conclusions References

Tables Figures

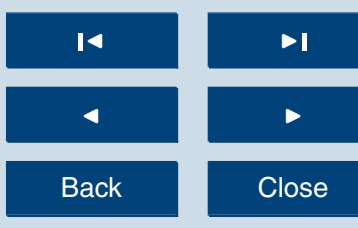

Full Screen / Esc

Printer-friendly Version

Interactive Discussion 
drift could also mean that the stratification from the temperature climatology (WOA 2001) is not consistent with the surface forcing fluxes (ERA40), which is likely as in situ data are extremely rare at high southern latitudes.

\subsection{Inversion performance}

5 As the MLD inversion is based on the fit to observed SST, its performance can be evaluated through the temperature error, defined as the difference between the simulated temperature and the SST input. The annual mean error (Fig. 8) is low over most of the global ocean $\left(<0.5^{\circ} \mathrm{C}\right)$, thus the model temperature stays generally close to the observations. Indeed, the algorithm converges with a daily error lower than $0.01^{\circ} \mathrm{C}$ in more than $50 \%$ of the cases.

Despite this good overall performance, small errors can cumulate all year long and lead to a significant drift. The simulated temperature exhibits a clear negative bias over several regions. At inter-tropical latitudes, the mean error reaches $-2^{\circ} \mathrm{C}$ over thin bands along the northern ITCZs in the eastern Pacific, western Atlantic and Indian Ocean, and even exceeds $-3^{\circ} \mathrm{C}$ over a broader area in the tropical north-western Pacific. The negative temperature bias indicates that the downward entrainment overcompensates for the surface heat input.

At midlatitudes, errors are larger (up to $-5^{\circ} \mathrm{C}$ ), within the WBCs and their extensions, as expected from the MLD drift (Fig. 7). In these areas, advection is as important as the

air-sea flux, so this defect could arise from inconsistencies between the air-sea heat flux (from the ECMWF meteorological model) and the geostrophic currents (from the SSALTO-DUACS altimeter data). As the errors are systematically negative, the vertical adjustment of the simulated mixed layer is not sufficient to ensure thermal equilibrium. Adding a horizontal mixing mechanism in the model would help maintaining the SST fit

Temperature errors are also highly negative (from -1 to $-5^{\circ} \mathrm{C}$ ) along the AACC, where intense advection could lead to overestimating the mixed layer cooling. Alternatively, as the thermal stratification is weak in this region, a slight underestimation of the

OSD

4, 41-106, 2007

SSS variability from a global MLM

S. Michel et al.

Title Page

Abstract Introduction

Conclusions References

Tables Figures

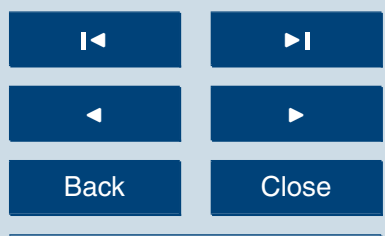

Full Screen / Esc

Printer-friendly Version

Interactive Discussion

EGU 
vertical temperature gradient can lead to very deep entrainment during winter. Finally, the errors indicate a slightly positive annual tendency (around $+2^{\circ} \mathrm{C}$ ) along the limit of sea ice in both hemispheres, because the model overestimates the warming due to poleward heat advection.

\section{Climatological salinity balance}

The previous section shows the inversion algorithm succeeds in reproducing the MLD variability and the SST seasonal evolution over most of the global domain. Moreover, the simulated heat budget has been analysed in several sub-domains, including the North-East Atlantic (Michel et al., 2006, submitted), the whole North Pacific (by comparison with Alexander et al., 2000) and the Kuroshio extension region (by comparison with Qiu and Kelly, 1993). In these three regions, the heat budget from the model lies within the range of estimates from previous studies. Thus, the model can be used to infer the salinity balance and to assess the SSS variability. Nonetheless, this analysis must be restricted to areas where MLD and SST are simulated accurately. Such areas can be defined from three simple criteria:

- the simulated MLD is highly correlated to observations (monthly correlation higher than 0.8),

- the MLD exhibits a weak annual drift (order of magnitude of $10 \mathrm{~m}$ ),

- the SST error is reasonably low (annual mean lesser than $1.0^{\circ} \mathrm{C}$ ).

20 As seen previously (Figs. 6, 7 and 8), the areas which do not satisfy all these criteria are located South of $50^{\circ} \mathrm{S}$ and North of $60^{\circ} \mathrm{N}$, as well as in the strongest WBCs and some small areas in the inter-tropical band. Therefore, the salinity budget and variability will not be discussed over these areas.
OSD

4, 41-106, 2007

SSS variability from a global MLM

S. Michel et al.

\section{Title Page}

Abstract Introduction

Conclusions

References

Tables

Figures

I

4

$>$ I

4

Back

Full Screen / Esc

Printer-friendly Version

Interactive Discussion 
The salinity balance computed from Eq. (2), as well as the temperature balance, is composed of six terms:

- The first term on the RHS of Eq. (2) stands for the impact of freshwater fluxes $(E-P-R)$ from atmosphere to ocean (precipitations), from ocean to atmosphere (evaporation) and from continents into ocean (river runoffs).

- The second and third terms, standing for horizontal advection, consist in the effects of Ekman transport $\left(U_{E}\right)$ and geostrophic currents $\left(u_{g}\right)$.

- The fourth and fifth term, standing for vertical entrainment, represent Ekman vertical advection (named "Ekman pumping") and vertical mixing across the mixed layer base (named "diapycnal mixing").

- The last term parameterizes horizontal processes at sub-grid scales (named "lateral diffusion").

The salinity balance in the mixed layer is first examined through the annual mean 15 freshen or salinize the mixed layer during the seasonal cycle.

Both horizontal advection terms (Fig. 9a,b) display high values over inter-tropical regions, along the WBCs and within the AACC. In the tropical Pacific and Atlantic, as the SSS minimum is located below the northern ITCZ (around $5^{\circ} \mathrm{N}$ ), the Ekman divergence tends to increase salinity North of equator and decrease it South of equator. On the contrary, geostrophic westward jets decrease salinity along $2^{\circ} \mathrm{N}$ and increase it along $2^{\circ} \mathrm{S}$. These effects are more obvious East of both basins, where SSS is particularly low. Around the Indonesian archipelago, surface water is freshened by heavy precipitations and runoffs. Thus, eastward geostrophic currents decrease salinity in the western part of equatorial Pacific and increase it in the eastern part of Indian Ocean.
OSD

4, 41-106, 2007

SSS variability from a global MLM

S. Michel et al.

\section{Title Page}

Abstract Introduction

Conclusions References

Tables

Figures

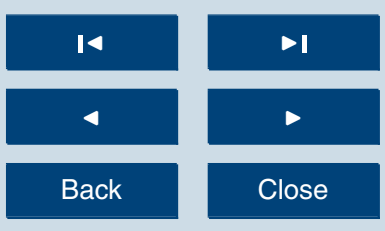

Full Screen / Esc

Printer-friendly Version

Interactive Discussion 
At tropical latitudes, the Ekman transport associated to Westerlies is directed poleward and freshens the high salinity waters from subtropical gyres. Geostrophic currents are strong within the WBCs, which advect fresher waters from the ITCZs and from large river mouths. In subtropical northern areas, winds blow mainly eastward, thus Ekman 5 transport is equatorward and decreases salinity by advecting fresher water from subpolar regions. This is particularly apparent within the Gulf Stream and Kuroshio, as they are associated with strong salinity gradients. The geostrophic transport of these currents exhibits an ambivalent effect. At large-scale, salinity decreases due to advection of fresher water by the mean flow, while some small areas exhibit a strong 10 salinisation, due to permanent northward meanders. Similarly, in the AACC, alternate northward/southward meanders generate a series of positive/negative features, with a typical wave length around $6-7^{\circ}$ in longitude. Ekman transport has a negative impact on salinity all along the AACC, as it advects fresh water northward from the ice sheet boundary. As for geostrophic currents, the effect of Ekman transport is particu15 larly strong downstream of Good Hope Cape, where the meridional salinity gradient is highest due to eastward entrainment of South Atlantic surface water.

In the vertical entrainment terms (Fig. 9c,d), the two contributions are not equivalent, in contrast with horizontal advection. Ekman pumping is significant only in inter-tropical areas, where it is generally positive due to equatorial upwelling which mixes the surface waters (freshened by rain or runoffs) with deep salty water. A few exceptions are found where upwelling occurs below saltier surface water, due to the presence of a densitycompensated layer (as in the Indian Ocean, around $5^{\circ} \mathrm{N}-60^{\circ} \mathrm{E}$ ), or where downwelling freshens the mixed layer (as in the north-eastern equatorial Pacific and Atlantic). At higher latitudes, coastal upwelling marginally affects salinity, but this effect is hampered by the coarse resolution of the model.

Diapycnal mixing appears to be much more important at most latitudes. In tropical areas, it induces a strong salinisation, with peak values at the location of the strongest vertical salinity gradient, i.e. close to the major rivers mouths. At subtropical latitudes, the maximum salinity waters at the centre of subtropical gyres mix with fresher waters
OSD

4, 41-106, 2007

SSS variability from a global MLM

S. Michel et al.

\section{Title Page}

Abstract Introduction

Conclusions References

Tables Figures

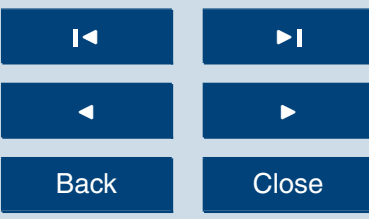

Full Screen / Esc

Printer-friendly Version

Interactive Discussion 
at depth, thus the contribution is negative. Conversely, the contribution is highly positive along the northern edges of Gulf Stream and Kuroshio, where the vertical salinity gradient is particularly. In a similar fashion, the southern edge of AACC limits the fresh water penetration from the Antarctic Ocean, thus diapycnal mixing exhibit a highly pos5 itive effect. In the subpolar North Atlantic, this process reaches its highest values due to deep winter convection, particularly in the Labrador Sea and West Greenland Sea.

The spatial pattern of net freshwater flux is well-known, but its impact on the mixed layer salinity is modulated by MLD and by salinity itself, as seen in Eq. (2). Thus the distribution of the surface flux impact on salinity (Fig. 9e) is slightly different from the

$10 E-P$. The contribution from river runoffs $R$ is not clearly visible on a global map, as this flux is concentrated at a few points against the coastal boundaries. Nonetheless, its impact can be important over large areas, through advection of fresh water and diffusion across the strong horizontal gradients associated with river mouths. The largest impact of air-sea flux consists in an intense freshening over the ITCZs. These areas are 15 limited poleward by high evaporation-dominated regions within the subtropical gyres. High positive impacts are also found in semi-enclosed areas, such as the Mediterranean Sea, Red Sea and Gulf of Oman. At subtropical latitudes, the freshwater flux impact is weaker, because $E$ and $P$ fluxes are lower and MLD is larger, thus smaller surface anomalies are mixed within a thicker water column. A significant contribution 20 itations, with an impact lower than in inter-tropical areas by one order of magnitude. Similarly, moderate rain over the Southern Ocean gives rise to a slight desalinisation along the AACC, but only at its northern edge, as MLD is rather deep within the current core.

25 Finally, lateral diffusion (Fig. 9f) is negligible over most open oceans, but it can equal other processes in the vicinity of the strongest SSS horizontal gradients. Therefore diffusion exhibits a considerable negative effect around large rivers outputs, in particular those of the Amazon and Rio de la Plata. As explained above, the Gulf Stream is characterized by a strong southward salinity gradient, thus the contribution of diffusion
OSD

4, 41-106, 2007

SSS variability from a global MLM

S. Michel et al.

\section{Title Page}

Abstract Introduction

Conclusions References

Tables Figures

I

14

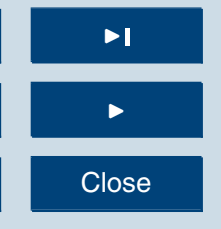

Full Screen / Esc

Printer-friendly Version

Interactive Discussion 
is positive (resp. negative) North (resp. South) of the current. In the subpolar North Atlantic, diffusion freshens the interior of the Nordic Seas and increases salinity close to ice sheet boundaries.

\section{OSD}

4, 41-106, 2007

\subsection{Processes variability}

5 To further understand the role of the various processes in the SSS evolution, we examine their annual variability, computed as the standard deviation of daily anomalies. For processes which sign reverses during the seasonal cycle, the impact is better quantified from standard deviation than from annual mean. This variability analysis reveals the dominant processes in each part of the global ocean, and subsequently the most 10 important forcing data and the most critical parameterisations.

The standard deviation of each term in the salinity balance (Fig. 10) is generally lower than $20 \times 10^{-3}$ psu.day $^{-1}$ (equivalent to $\sim 7$ psu.year $^{-1}$ ). Only a few limited areas exhibit a higher variability, essentially over the inter-tropical band, along the WBCs, in the northern subpolar regions and within the AACC. We describe each of these four types of area successively, in order to determine the dominant processes. At inter-tropical latitudes, the precipitations impact is very strong (as shown in Fig. 9e), as well as the contribution of horizontal advection. Ekman transport is particularly important in the western Atlantic (due to Trade winds blowing over the Amazon plume) and eastern Indian Ocean (due to Monsoon winds and strong salinity gradients in the Bay of Bengal). Geostrophic advection plays a fundamental role close to the equator, mainly in the western parts of the Pacific and Atlantic, where intense westward jets flow from freshened areas. Vertical entrainment plays a secondary role at low latitudes, as the diapycnal mixing impact is generally lower than $5 \times 10^{-3}$ psu.day $^{-1}$, except within major rivers plumes. Ekman pumping reaches $10 \times 10^{-3}$ psu.day ${ }^{-1}$ only in the vicinity 25 of large rivers where the wind blows parallel to the continents. The contribution of horizontal diffusion does not exceed $5 \times 10^{-3}$ psu.day $^{-1}$, even inside the main river plumes.

Within the WBCs, the main contributor to salinity variations appears to be
SSS variability from a global MLM

S. Michel et al.

\section{Title Page}

Abstract Introduction

Conclusions References

Tables Figures

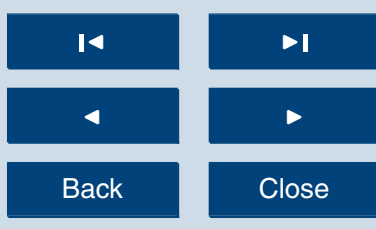

Full Screen / Esc

Printer-friendly Version

Interactive Discussion 
geostrophic transport. These currents advect either freshened waters from river plumes and ITCZs, as in the case of the North Brazil Current, or salty waters from tropical latitudes, as the Brazil-Malvinas Confluence and the Gulf Stream, where the variability exceeds $20 \times 10^{-3}$ psu.day $^{-1}$. This is also the case for the Kuroshio, but to 5 a lesser degree (around $5 \times 10^{-3}$ psu.day $^{-1}$ ) because the meridional salinity gradient is lower in the Pacific. The Ekman transport contribution is important over the Amazon plume (more than $10 \times 10^{-3}$ psu.day $^{-1}$ ) and along the Gulf Stream (up to $6 \times 10^{-3}$ psu.day ${ }^{-1}$ ), because the dominant winds blow parallel to the strong haline fronts induced by geostrophic currents. This is less obvious within the Kuroshio (less than $102 \times 10^{-3}$ psu.day $^{-1}$ ), because the associated haline front is weaker. The impact of diapycnal mixing is important (exceeding $10 \times 10^{-3}$ psu.day $^{-1}$ ) poleward of these haline fronts, where relatively fresh water lie above salty water. The air-sea flux impact is significant along the cores of the Gulf Stream and Kuroshio (around $5 \times 10^{-3}$ psu.day $^{-1}$ ), as these currents transport warm surface waters which enhance precipitations along 15 their paths.

In northern subpolar areas, salinity variability is quasi-exclusively controlled by diapycnal entrainment (exceeding $20 \times 10^{-3}$ psu.day $^{-1}$ ), particularly in the Labrador Sea, West Greenland Sea and North Pacific. This process is important all year long, because of the stratification induced by ice melting during spring and summer, then the convection due to intense surface cooling in fall and winter. Geostrophic advection plays a secondary role in these regions, where coastal currents transport freshened water from ice-covered areas. Ekman advection is large only in the Denmark Strait (up to $10 \times 10^{-3}$ psu.day $^{-1}$ ), where westward wind induces a northward transport across the salinity front, counteracting the effect of geostrophic current. The impact of lateral diffusion appears significant along the sea ice boundaries, particularly in the northern Labrador Sea and Arctic Ocean (reaching $4 \times 10^{-3}$ psu.day $^{-1}$ locally).

At southern subpolar latitudes, salinity variability is governed either by horizontal advection or by vertical entrainment. Along the AACC northern edge, geostrophic advection plays a dominant role (approximately $10 \times 10^{-3}$ psu.day ${ }^{-1}$ ) by transporting

OSD

4, 41-106, 2007

SSS variability from a global MLM

S. Michel et al.

Title Page

Abstract Introduction

Conclusions References

Tables Figures

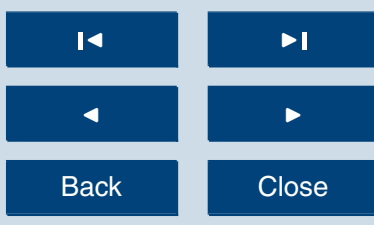

Full Screen / Esc

Printer-friendly Version

Interactive Discussion 
waters across the strong zonal front located around $45^{\circ} \mathrm{S}$, through its large NorthSouth meanders (apparent in Fig. 9b). Ekman advection plays a much smaller role in this area (less than $2 \times 10^{-3}$ psu.day $^{-1}$ ), due to weak equatorward transport across the front. Along the AACC southern edge, salinity variations are mainly attributed to diapycnal mixing. The related mechanism is similar to the stratification/convection cycle in the North Atlantic, but on a much larger spatial scale and with a lower intensity (between 10 and $20 \times 10^{-3}$ psu.day $^{-1}$ ).

\subsection{Processes contribution to the global budget}

The salinity balance is described more synthetically by determining the dominant process at each point of the domain. This is achieved by computing the annual mean amplitude $a_{i}$ of each term (for $i=1, \ldots, 6$ ), then by dividing each mean by their sum $b$, to obtain the contribution $c_{i}$ :

$$
\begin{gathered}
a_{i}(x, y)=\overline{\left(\partial_{t} S_{i}(x, y, t)\right)} \\
b(x, y)=\sum_{j=6}^{j=6} a_{j}(x, y) \\
c_{i}(x, y)=\frac{a_{i}(x, y)}{b(x, y)}
\end{gathered}
$$

The dominant process is the term $i$ corresponding to the highest contribution. The map of dominant processes is useful to summary the salinity balance, but is not relevant in areas where two or more processes have similar contributions. However, it highlights the conclusions from previous sections (Sects. 4.1 and 4.2) and provides additional information on areas where every terms exhibit low intensity.

The distribution of the dominant process (Fig. 11) confirms that salinity variations are primarily controlled by the freshwater fluxes in the tropical northern Atlantic, the tropical northern and south-western Pacific (where precipitations dominate due to ITCZs) and in the central parts of the subtropical gyres (where evaporation dominates). Ekman transport dominates essentially over the Trade wind areas. Geostrophic advection
OSD

4, 41-106, 2007

SSS variability from a global MLM

S. Michel et al.

\section{Title Page}

Abstract Introduction

Conclusions References

Tables Figures

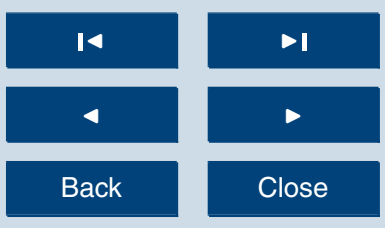

Full Screen / Esc

Printer-friendly Version

Interactive Discussion 
dominates along almost all the equatorial band, over the northern part of the subtropical gyres, most of the subpolar gyres, in the WBCs and along the AACC northern part. Diapycnal entrainment plays the main role at some gyre boundaries, over areas of deep water formation in the North Atlantic and Pacific, as well as all along the AACC 5 southern part. Lateral diffusion is the dominant process in a few narrow areas, for instance in the plume of Rio de la Plata and over parts of the North-West European Shelf.

The globally averaged contributions are indicated in Table 2, in terms of annual mean value (corresponding to Fig. 9), annual mean amplitude (similar to the standard devia10 tions in Fig. 10) and relative amplitude (leading to the major term distribution displayed in Fig. 11). The salinity balance is expected to be more reliable over the ice-free ocean, where the forcing data are more accurate and the simulated MLD is more consistent with observations (Sect. 3.3). Therefore, all the global averages are computed over the domain which is never covered with sea-ice during any day of the climatological 15 year ( $85 \%$ of the ocean points). For readability reasons, the salinity variation unit, $10^{-3}$ psu.day ${ }^{-1}$, is omitted in the following paragraph.

The global mean values (1st column in Table 2) reveal that the freshwater flux implies a net freshening of the upper ocean $(-1.9)$. Indeed, precipitations slightly dominate evaporation in the ECMWF model (the globally averaged $E-P$ is equal to -0.1 $20 \mathrm{~mm}$ day $^{-1}$ ) and the runoffs add a substantial negative contribution to the freshwater budget (equivalent to a flux of $-0.3 \mathrm{~mm}_{\text {.day }}{ }^{-1}$ ). Moreover, precipitations produce shallow mixed layers, while evaporation induces thicker mixed layers, thus the impact of $P$ on SSS is generally stronger than the impact of $E$. In contrast, vertical entrainment exhibits a highly positive contribution $(+1.8)$, because it always tends to increase 25 the mixed layer salinity. Its effect is mainly due to diapycnal mixing $(+1.5)$, which is generally much stronger and more wide-spread than Ekman pumping (+0.3). The mean effect of advective terms is significantly lower $(-0.9)$. The geostrophic contribution is weak $(-0.2)$, indicating that currents have no preferred direction across the SSS fronts, while the Ekman contribution is clearly negative (-0.7). At low latitudes,
OSD

4, 41-106, 2007

SSS variability from a global MLM

S. Michel et al.

Title Page

Abstract Introduction

Conclusions

References

Tables

Figures

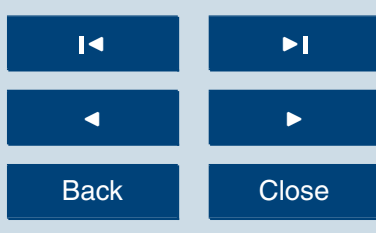

Full Screen / Esc

Printer-friendly Version

Interactive Discussion 
wind-induced transport is often directed poleward, so it brings freshened waters (due to rain or runoffs) from inter-tropical band to subtropical areas. Conversely, at high latitudes, Ekman transport is generally directed equatorward, bringing ice-melt water toward subpolar regions. The diffusive contribution is almost zero, because this pro5 cess mixes waters equally in both down-gradient and counter-gradient directions.

In summary, the global salinity balance is governed by an opposition between vertical entrainment, which systematically increases salinity, and the combination of surface flux and horizontal advection, which overall tend to decrease salinity. The total tendency indicates a net freshening by $-1.05 \times 10^{-3}$ psu.day $^{-1}$, equivalent to an annual 10 variation of -0.38 psu.year $^{-1}$. Note that this tendency is reversed if ice-covered areas are included (because of the salinisation due to vertical entrainment). Therefore, the global SSS tendency is very sensitive to the simulation of the mixed layer in polar regions. In terms of salt fluxes $\left(F_{S}=\rho_{0} / \rho_{f} h \partial_{t} S, \rho_{0}\right.$ being the seawater density and $\rho_{f}$ the freshwater density), the global budget is slightly positive over the ice-free do15 main. Thus the simulated salinity tends to decrease inside shallow mixed layers and increase inside thick mixed layer. The global salt balance (not shown) reveals that this salt injection into the upper ocean is essentially due to diapycnal mixing.

In terms of annual amplitude (mean absolute value of each process, 2nd column in Table 2), diapycnal mixing is only the third contributor to the global variations (2.2). 20 Geostrophic advection (4.1) exhibits the most important contribution, while the contribution of Ekman transport is approximately half lower (2.2). The total advection amplitude (3.7) is smaller than its geostrophic component, which implies that Ekman transport is generally opposed to the effect of geostrophic currents. The surface flux contribution (3.3) is slightly weaker than total advection. Ekman pumping is affected 25 with the smallest impact (0.6), even lower than lateral diffusion (0.9). Finally, the total salinity variations exhibit a global amplitude of $8 \times 0^{-3}$ psu.day $^{-1}$. Note that this value corresponds to daily fluctuations, which are one order of magnitude lower than seasonal variations (analysed below, see Fig. 12). The sum of the mean amplitudes (13.1) is significantly higher than the mean of the total amplitude, confirming that compen-

OSD

4, 41-106, 2007

SSS variability from a global MLM

S. Michel et al.

Title Page

Abstract Introduction

Conclusions References

Tables Figures

I

14

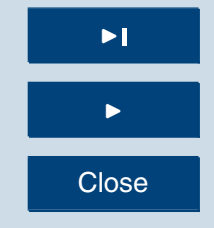

Full Screen / Esc

Printer-friendly Version

Interactive Discussion 
sations occur between some processes, as expected from the mean values of each term.

The local relative contributions (3rd column in Table 2) indicate the impact of each term on local salinity variations. In contrast with the previous diagnostics, this quantity

5 is not computed from the global averages of the processes, but from the local contributions $c_{i}(x, y)$ defined by Eq. (5), integrated over the simulation duration. For example, in the case of diapycnal mixing, the contribution to the mean amplitude is $2.2 / 13.1=$ $17 \%$, but its average local contribution is $22 \%$. This difference implies that this term is particularly important in areas with low salinity variations. Geostrophic advection 10 also dominates the local salinity balance (33\%), while the impact of Ekman advection is three times smaller (13\%). However, Ekman terms are not computed in the equatorial band $\left(3^{\circ} \mathrm{S}-3^{\circ} \mathrm{N}\right)$ (because of the divergence of the Coriolis parameter $f$ ), where their contributions are expected to be determinant. The local effect of surface flux is considerably less important $(22 \%)$ than advection. The contribution of lateral diffusion

15 is much weaker, though significant (8\%) and the effect of Ekman pumping is generally negligible (3\%). Thus horizontal advection also appears as the main process $(46 \%)$ in the local salinity balance, clearly dominating vertical entrainment $(24 \%)$ and surface flux.

\section{Salinity variability}

20 The total salinity variations arise from the combination of the six processes, described above in terms of annual tendency (Sect. 4.1), seasonal variability (Sect. 4.2) and global contribution (Sect. 4.3). The salinity variability our mixed layer model should be validated against in situ estimates characterized by the same time and space scales (1 day and approximately 100, respectively). As no global salinity observations are available with such a high time sampling, we use the World Ocean Atlas 2001 (hereafter, WOA01) monthly climatology. This climatology is used in the simulation (see Appendix A) to initialize the salinity and to compute its vertical gradient, thus it can not be con-

OSD

4, 41-106, 2007

SSS variability from a global MLM

S. Michel et al.

\section{Title Page}

Abstract Introduction

Conclusions References

Tables Figures

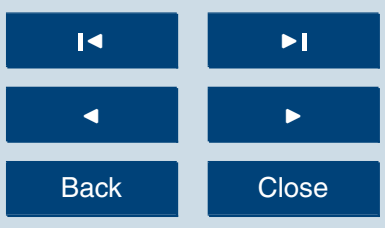

Full Screen / Esc

Printer-friendly Version

Interactive Discussion 
sidered as a strictly independent dataset. However, the comparison between these observations and the simulation highlights the spatial and temporal variations added by the model, as the climatology only provides the large-scale and slow background of the salinity.

\section{$5 \quad 5.1$ Seasonal variability}

The salinity variability from the simulation is compared to the SSS variability from WOA01 in terms of monthly standard deviation, computed as follows:

$\sigma_{m}(x, y)=\left\{\frac{1}{12} \sum_{m=1}^{m=12}[S(x, y, m)-\bar{S}(x, y)]^{2}\right\}^{\frac{1}{2}}$

where $S(x, y, m)$ is the mean of salinity for a month $m$ and $\bar{S}(x, y)$ is the annual mean 10 salinity at a grid point $(x, y)$.

The SSS variability from the WOA01 climatology (Fig. 12a) is concentrated in three types of areas: river plumes, salty water inputs and subpolar fronts. The variability maxima of each basin are associated with the major river outputs. The maximum $\sigma_{m}$ range from 9.5 psu in the Amazon plume, 6.1 in the Gange plume, $1.4 \mathrm{psu}$ in the 15 Chimborazo and 0.7psu in the Yang Tse Kiang, for the Atlantic, Indian, eastern and western Pacific basins, respectively. The salinity variability in these plumes is related to the runoffs intensity and to the freshwater spreading by oceanic currents. The second type of maxima is due to displacements of salty waters, generally originating from semi-enclosed seas, such as the Persic Gulf (1.7 psu) and the Red Sea (0.4 psu). The third type of maxima is associated with strong haline fronts in subpolar areas, due to advection of ice-melt waters. For instance, $\sigma_{m}$ is particularly high at the output of the Labrador Sea (6.7 psu) in the Atlantic, Bering Sea (1.8 psu) in the northern Pacific and Ross Sea $(0.9 \mathrm{psu})$ in the southern Pacific. Note that the variability appears also very high over the whole Arctic Ocean and in the Hudson Bay, but its quantification is uncertain because of frequent sea-ice coverage and lack of in situ data.
OSD

4, 41-106, 2007

SSS variability from a global MLM

S. Michel et al.

\section{Title Page}

Abstract Introduction

Conclusions References

Tables Figures

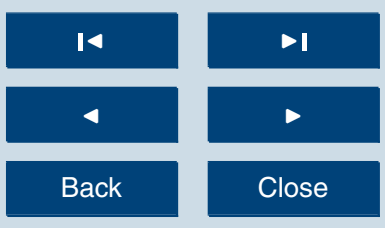

Full Screen / Esc

Printer-friendly Version

Interactive Discussion 
The simulation reproduces the location of these maxima (Fig. 12b), which represent the first order of the salinity variability. This was expected from the mixed layer model, as such maxima are caused either by river runoffs or by strong haline fronts which are already depicted in the climatology. In the inter-tropical band, the variabil5 ity is enhanced both in the climatology and the simulation. The simulated variability is considerably higher, because the simulation is forced with daily data. For instance, the climatological $\sigma_{m}$ does not exceed 0.4 psu in the north-eastern tropical Pacific and $0.6 \mathrm{psu}$ in the northern central Indian Ocean, where the simulated $\sigma_{m}$ reaches 2.0 and $1.2 \mathrm{psu}$, respectively. The simulated variability is amplified closer to the equator. In 10 the tropical Atlantic, the climatology exhibits high values $\left(\sigma_{m}>0.2\right)$ between $15^{\circ} \mathrm{S}$ and $20^{\circ} \mathrm{N}$, while in the simulation they are restricted to $10^{\circ} \mathrm{S}-12^{\circ} \mathrm{N}$. In the northern tropical Pacific, the climatology shows a broad high variability area in the eastern part (centred on $12^{\circ} \mathrm{N}-125^{\circ} \mathrm{W}$ ), whereas in the simulation the variability is higher in the western part (from the Indonesian Archipelago to $165^{\circ} \mathrm{E}$ ). Conversely, in the northern Indian 15 Ocean, the climatological maximum is found in the western part (Arabic Sea), while its simulated counterpart lies in the eastern part (Bay of Bengal). Such shifts in longitude are likely to be caused by errors in the forcing fluxes from the ECMWF model, which are enhanced over ITCZs (see Sect. 3.5). The freshwater flux impacts directly the simulated SSS, while the net surface heat flux had an indirect effect through MLD.

20 For instance, in the north-eastern tropical Pacific, precipitations are overestimated and MLD is too shallow, resulting in too strong a desalination over the rain-induced fresh pool.

At subtropical latitudes, variability maxima are found along the WBCs in the climatology as well as in the simulation. The simulated $\sigma_{m}$ is much higher, with local maxima

around $2.0 \mathrm{psu}$ in the Gulf Stream and $1.5 \mathrm{psu}$ in the Kuroshio, while in the climatology they do not exceed 0.4 and 0.2 psu, respectively. Such differences are reasonable, since the frequency of the geostrophic current data is a few days, while the climatology is monthly. Similarly, because of the small scales in the geostrophic forcing, the simulated salinity structures are finer (down to the model grid resolution, $1.125^{\circ}$ ) than in
OSD

4, 41-106, 2007

SSS variability from a global MLM

S. Michel et al.

Title Page

Abstract Introduction

Conclusions References

Tables Figures

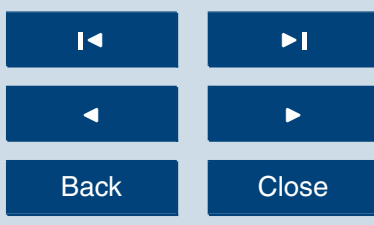

Full Screen / Esc

Printer-friendly Version

Interactive Discussion 
the climatological fields (constructed using an optimal interpolation with influence radii around $\left.3^{\circ}\right)$. Away from the WBCs, the observed variability is very small $\left(\sigma_{m}<0.1 \mathrm{psu}\right)$, except at the centre of the subtropical gyres. The simulation exhibits a significant variability over most of the subtropical gyres $\left(\sigma_{m} \sim 0.1 \mathrm{psu}\right)$, due to daily fluctuations in the 5 forcing fields, but the local maxima are properly located at the centres. A more detailed analysis reveals that the observed maxima in the Pacific gyres $(0.3$ and $0.2 \mathrm{psu}$ in the northern and southern parts) are twice higher than in the Atlantic gyres (0.2 and $0.1 \mathrm{psu}$, respectively), a contrast which is reproduced in the simulation ( 0.6 and $0.4 \mathrm{psu}$ in the Pacific, 0.3 and 0.2 in the Atlantic).

10 In subpolar regions, salinity variability is enhanced in the WBCs extensions. Thus, an area of high variability $\left(\sigma_{m}>0.2 \mathrm{psu}\right)$ extends eastward within the North-Atlantic Drift, to $30^{\circ} \mathrm{W}$ in the climatology and $20^{\circ} \mathrm{W}$ in the simulation. An equivalent area is found in the Kuroshio extension region, extending at least to $160^{\circ} \mathrm{W}$ in the climatology and the simulation. But its eastern limit is less obvious, as it merges with the region of freshened water from the Bering Sea. In the Norwegian Sea, the simulation exhibits some high variability features $\left(\sigma_{m} \sim 1.0 \mathrm{psu}\right)$, associated with fine scale geostrophic currents (see Fig. 10b), which are not represented in the observations. At southern subpolar latitudes, the climatological variability is extremely low $\left(\sigma_{m}<0.05 \mathrm{psu}\right)$ all along the AACC and relatively high along both edges, the subpolar front (up to $0.2 \mathrm{psu}$ ) and the

extension limit of the Antarctic ice-sheet (up to $0.3 \mathrm{psu}$ ). The simulated variability is also enhanced along the subpolar front (up to $1.0 \mathrm{psu}$ ), especially at the longitudes of the western Indian Ocean, where the meridional salinity gradient is highest. But the AACC core is affected with a variance maximum, due to diapycnal mixing in the model (see Fig. 10d). In this area, the model adjusts to the atmospheric forcing and the geostrophic currents through large MLD variations. A stable solution can not be found all the time, because the various forcing data are not consistent, resulting in an overestimation of MLD and SSS variability.
OSD

4, 41-106, 2007

SSS variability from a global MLM

S. Michel et al.

Title Page

Abstract Introduction

Conclusions

References

Tables

Figures

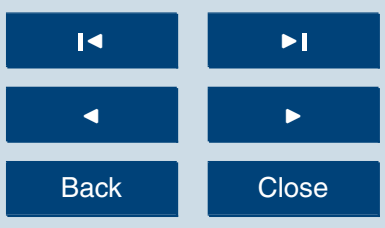

Full Screen / Esc

Printer-friendly Version

Interactive Discussion 
The model enables to investigate the salinity variability at time scales smaller than in the climatology (from one day to one month). No in situ estimate is available to validate this high-frequency variability over the global domain, but it cam be compared 5 to the seasonal variability. The intensity of day-to-day fluctuations is represented by the standard deviation of daily increments:

$\sigma_{d}(x, y)=\left\{\frac{1}{365} \sum_{t=1}^{t=365}[S(x, y, t)-S(x, y, t-1)]^{2}\right\}^{\frac{1}{2}} \approx\left\{\overline{\partial_{t} S(x, y, t)^{2}}\right\}^{\frac{1}{2}}$

The typical values of the daily variability $\sigma_{d}($ Fig. 13) are one order of magnitude lower than those of the monthly variability $\sigma_{m}$ (Fig. 12b). It reaches 0.1 psu over the northern 10 seas and the largest rivers plumes. In tropical oceans, the daily fluctuations magnitude is around 0.01 psu below ITCZs and it reaches 0.03 psu at some small locations, mainly in the Pacific. Thus the highest daily variations are not distributed like the seasonal variability. Moreover, $\sigma_{d}$ is higher in the Gulf Stream and along the northern edge of the Kuroshio (up to $0.05 \mathrm{psu}$ ) than within equatorial jets, in contrast with $\sigma_{m}$. 15 The daily variability is also enhanced along the AACC core and within the southern subpolar front, downstream of the South African tip (up to 0.03 psu locally). Thus the variability reaches the same values as in the equatorial band at daily scales, whereas it is considerably lower at seasonal scale. Consequently, in inter-tropical areas, salinity variations are essentially characterised by the seasonal cycle, while in subtropical and subpolar currents they include a significant contribution of higher frequencies.

The daily variability distribution reveals that fast salinity fluctuations are especially low (down to $0.001 \mathrm{psu}$ ) over some regions at midlatitudes. The most widespread area lies in the southern Pacific (along $45^{\circ} \mathrm{S}$, between $170^{\circ} \mathrm{W}$ and $115^{\circ} \mathrm{W}$ ) and some less extended areas are found in the north-eastern Atlantic (around $45^{\circ} \mathrm{N}-15^{\circ} \mathrm{W}$ ), in 25 the south-western Indian Ocean (around $35^{\circ} \mathrm{S}-60^{\circ} \mathrm{E}$ ) and to the South of Australia (around $45^{\circ} \mathrm{S}-130^{\circ} \mathrm{E}$ ). The simulated mixed layer is not particularly thick over these

4, 41-106, 2007

SSS variability from a global MLM

S. Michel et al.

\section{Title Page}

Abstract Introduction

Conclusions References

Tables Figures

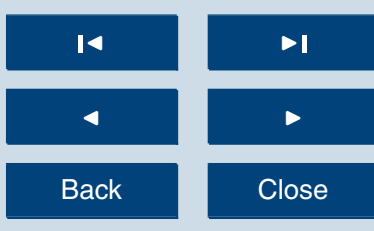

Full Screen / Esc

Printer-friendly Version

Interactive Discussion 
areas (see Fig. 3 and Fig. 4), thus the salinity stability is due low variability in the forcing fields. Indeed, such areas are characterized by weak geostrophic currents and steady winds and freshwater fluxes. Thus, over these four areas, surface salinity variations are negligible at seasonal to daily scales.

\section{$5 \quad 5.3$ Annual mean salinity}

The annual mean salinity from the simulation is compared to SSS mean in the WOA01 climatology, although these two estimates are intrinsically different. Indeed, the model salinity represents an average over the mixed layer depth, but at seasonal scale it is expected to be very similar to the sea surface salinity. Moreover, most in situ measurements are realised at a few meters depth (generally between 1 to $10 \mathrm{~m}$ ), so the top level in the climatology corresponds to a vertically integrated layer, away from surface skin effects.

The global distribution of the simulated salinity is similar to the observed SSS distribution (Fig. 14), in spite of its highest seasonal variability (Fig. 12) and additional daily variations (Fig. 13). Superimposed on these large-scale structures, the simulation presents features at smaller scales and stronger horizontal gradients. The two salinity maxima in the Atlantic subtropical gyres are prominent in the climatology, the northern one being stronger $\left(37.5 \mathrm{psu}\right.$ around $\left.25^{\circ} \mathrm{N}\right)$ and wider than the southern one (37.25 psu around $20^{\circ} \mathrm{S}$ ). In the simulation, these maxima are stronger and closer to 20 the equator ( $38.0 \mathrm{psu}$ at $20^{\circ} \mathrm{N}$ and $37.75 \mathrm{psu}$ at $15^{\circ} \mathrm{S}$, respectively). The shapes of these high salinity areas are also slightly different from the climatology, as the northern area is more zonally elongated and the southern one is located closer to the coast of Brazil. In the subtropical Pacific, the simulated maxima are also nearer to the equator, but their values are very close to the observations (35.75 in the northern gyre and $2536.5 \mathrm{psu}$ in the southern one). In the Indian Ocean, the southern maximum at $30^{\circ} \mathrm{S}$ lies closer to the western coast of Australia than in the observations and exhibits a higher value (36.75 instead of $36.75 \mathrm{psu}$ ). Such differences are linked to the combined effect of local evaporation, which create the SSS maxima, and horizontal advection, which
OSD

4, 41-106, 2007

SSS variability from a global MLM

S. Michel et al.

Title Page

Abstract Introduction

Conclusions References

Tables Figures

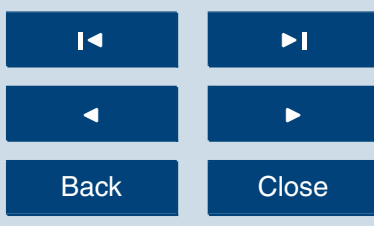

Full Screen / Esc

Printer-friendly Version

Interactive Discussion 
displace and distort salty water areas (Fig. 9a,b,e). A more pronounced difference is found in the Gulf of Oman, where the climatology exhibits a 36.5 psu maximum at the northern end, while the simulation generates a $37.5 \mathrm{psu}$ maximum at the centre of the gulf. This local maximum is due to gesotrophic advection of salty water from the Bay of 5 Bengal (Fig. 10b), a feature which scale is too small to be captured in the climatology. In inter-tropical regions, the climatology exhibits local minima below the ITCZs, particularly in the northern Pacific and the southern Indian Ocean. These features are well located in the simulation, but the surface freshening appears stronger. In particular, in the north-eastern equatorial Pacific, the climatology shows a freshened water 10 tongue $(\mathrm{S}<34.0 \mathrm{psu})$ along $10^{\circ} \mathrm{N}$, from the coast of South America to $120^{\circ} \mathrm{W}$, while in the simulation it extends all across the basin. In the southern Pacific, a salinity minimum originates from the coast of Indonesia along $12^{\circ} \mathrm{S}$ and extends to $180^{\circ} \mathrm{E}$ in the climatology, whereas it continues to $150^{\circ} \mathrm{W}$ in the simulation. Similarly, in the southern Indian Ocean, the salinity minimum along $10^{\circ} \mathrm{S}$ is stronger and extends further East 15 in the simulation. These too large areas with low salinity are partially due to overestimated precipitations (see Sect. 4.1), but also to deficiencies in the surface heat flux causing too shallow MLD, and occasionally to the presence of salt barrier in the climatological salinity profiles. In equatorial areas, several spurious extrema are found (mainly in the Atlantic and the eastern Pacific), probably due to the suppression of the Ekman transport and pumping within the $3^{\circ} \mathrm{S}-3^{\circ} \mathrm{N}$ band.

At subpolar latitudes, the model maintains properly the salty waters ( $\mathrm{S}>35.0 \mathrm{psu}$ ) in the North Atlantic. The mixed layer salinity is considerably lower over the Grand Banks region, because of the fresh water import by the southward boundary current. In both the climatology and the simulation, the salinity is less than $33.0 \mathrm{psu}$ to the North of 25 the Gulf Stream, but the freshened area extends further East in the simulation $\left(35^{\circ} \mathrm{W}\right.$ instead of $40^{\circ} \mathrm{W}$ ). In the North Pacific, the salinity falls below 33.0 psu to the North of $40^{\circ} \mathrm{N}$ in the climatology and $35^{\circ} \mathrm{N}$ in the simulation, thus the meridional gradient of the simulated salinity is stronger. A small zonal band of high salinity appears to the North of the Kuroshio in the simulation and is too thin to be represented in the climatology. In
OSD

4, 41-106, 2007

SSS variability from a global MLM

S. Michel et al.

\section{Title Page}

Abstract Introduction

Conclusions References

Tables Figures

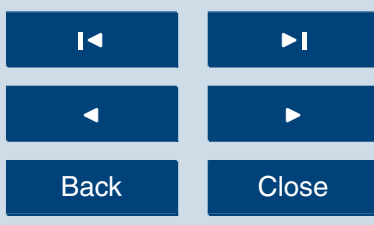

Full Screen / Esc

Printer-friendly Version

Interactive Discussion 
the southern oceans, the subpolar front is well located, i.e. around $35^{\circ} \mathrm{S}$ in the central Pacific and $45^{\circ} \mathrm{S}$ in the Atlantic and Indian Ocean. In the climatology, a salinity minimum is found all along the southern edge of the AACC, with values down to $33.5 \mathrm{psu}$. In the simulation, this minimum lies in the core of the AACC and reaches $33.0 \mathrm{psu}$. This 5 discrepancy is associated with a weak salinity maximum along the southern edge of the AACC (around $60^{\circ} \mathrm{S}$ ), with values up to $35.0 \mathrm{psu}$. This artificial feature is caused by the overestimation of diapycnal mixing (Fig. 9d), induced by inconsistencies in the forcing dataset.

\section{Conclusions}

\subsection{Summary}

Our simplified model is based on the "slab mixed layer" formulation (Frankignoul and Hasselmann, 1977), which bas been used mainly to investigate the temperature variability. The proposed model is designed to simulate the mixed layer salinity over the global ocean, thus it presents several original aspects:

- The surface freshwater flux consists in the evaporation minus precipitations budget from an atmospheric model, plus river runoffs from in situ measurements.

- The horizontal advection is split into an Ekman term depending on the MLD, computed from the wind stress, and a depth-averaged geostrophic term, estimated from satellite altimetry.

- The vertical entrainment consists in Ekman pumping, deduced from the wind stress curl, and diapycnal mixing, represented by the MLD variations.

- The deeper layer salinity, necessary to compute the entrainment effect, is obtained from an in situ climatology (preferred to using a 1D vertical mixing model, as in Alexander et al., 2000).
OSD

4, 41-106, 2007

SSS variability from a global MLM

S. Michel et al.

\section{Title Page}

Abstract Introduction

Conclusions References

Tables

Figures

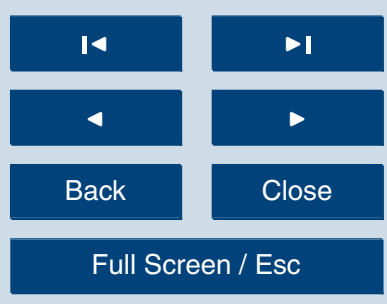

Printer-friendly Version

Interactive Discussion 
- The diapycnal mixing term represents in a simple way the effect of unresolved vertical processes (such as shear instability, internal wave breaking and lateral induction).

- The horizontal mixing is represented by a Laplacian diffusion operator with a constant diffusivity, providing an estimate for the mesoscale activity effect.

The model is integrated during a 1 -year long simulation, using a $1.125^{\circ}$ regular grid and a daily time-step. Climatological air-sea fluxes and SST data were computed from the last 12 years of the ERA40 reanalysis, when many satellite measurements were assimilated. Geostrophic currents were obtained from the 4-year SSALTO-DUACS, 10 using all the recent satellite altimeters. River runoffs are provided by an in situ global climatology (Dai and Trenberth, 2002). The deep layer temperature and salinity are extracted from the World Ocean Atlas 2001 monthly climatology.

Any mixed layer model requires the determination of an appropriate mixed layer depth. As the domain is global, the MLD can not be considered as a constant (as in 15 Mignot and Frankignoul, 2003). Moreover, to quantify the salinity balance, the MLD can not rely on an arbitrary criterion (as in Qiu and Kelly, 1993). Therefore, we use an inversion method to infer the MLD from observed temperature variations. Our algorithm is based on the temperature error minimization, while preserving a physically consistent MLD evolution. Two different computations are used in case of entrainment or detrainment of the mixed layer base. The method converges toward an acceptable MLD solution for more than $80 \%$ of situations, with temperature errors generally lower than $0.01^{\circ} \mathrm{C}$. This "effective depth" ensures consistency between the forcing dataset and the observed SST.

The resulting MLD variability is validated by comparison to the in situ thermocline depth from De Boyer-Montégut et al. (2004). The values can not be compared directly, but the spatial distributions in winter and summer are in fairly good agreement. Thus the model reproduces properly the location and time of the MLD minima in tropical and equatorial regions, as well as the maxima corresponding to deep water formation in the

OSD

4, 41-106, 2007

SSS variability from a global MLM

S. Michel et al.

\section{Title Page}

Abstract Introduction

Conclusions References

Tables Figures

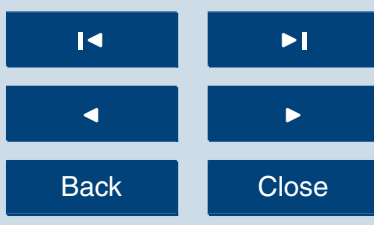

Full Screen / Esc

Printer-friendly Version

Interactive Discussion 
North Atlantic. However, the simulation slightly overestimates mixed layer deepening in the North Pacific, probably because of too weak a stratification in the climatology used for the deep layer. Along the AACC, the simulated depth reaches values as high as at northern high latitudes, while they should be restricted to small areas according to 5 observations. This deficiency could arise either from a missing process in the model, or from uncertainty in the forcing dataset, which is less reliable over the Antarctic Ocean than elsewhere. The time-correlation between the in situ thermocline depth and the simulated MLD are is remarkably high (more than 0.8) over most of the ocean. As expected, the agreement is poor in subpolar areas which are temporarily covered with 10 sea-ice. The correlation is weak in the inter-tropical band, because the mixed layer is shallow, thus more sensible to errors in the forcing fields. Nonetheless, this overall agreement, confirmed by the annual stability of the simulated MLD and SST, allows us to trust the salinity balance inferred from the model over most of the global domain.

The six processes governing the salinity evolution in the MLM exhibit very differ15 ent distributions and often antagonist effects. The surface freshwater flux induces a strong salinity decrease in the inter-tropical band and a weaker increase at midlatitudes. The Ekman transport impact is high near the equator, over the Trade wind regions and across haline fronts associated with intense steady currents. Geostrophic currents produce much smaller scales in the salinity field and their effect is important in equatorial zonal jets, in WBCS and along the AACC northern edge. Diapcynal mixing appears as an essential mechanism, not only in tropical areas characterised by freshened surface layers, but also in subtropical gyres where it counteracts the evaporation effect and at subpolar latitudes where it represents deep convection. Ekman pumping is much weaker and restricted to some inter-tropical divergence regions and a few coastal upwelling areas. Lateral diffusion is lower than the dominant processes by one order of magnitude, but it is significant within major rivers plumes and in haline fronts associated with strong currents or sea-ice melting. A synthetic view of the global salinity balance is obtained by plotting the dominant process at each grid point. Based on the global mean of their local impacts, the processes are sorted as follows (away

OSD

4, 41-106, 2007

SSS variability from a global MLM

S. Michel et al.

\section{Title Page}

Abstract Introduction

Conclusions References

Tables Figures

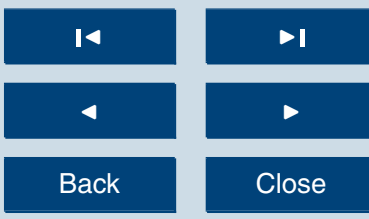

Full Screen / Esc

Printer-friendly Version

Interactive Discussion 
from the seasonally ice-covered areas): geostrophic advection (33\%), freshwater flux $(22 \%)$, diapycnal mixing (22\%), Ekman transport (13\%), lateral diffusion (8\%) and Ekman pumping $(3 \%)$. Note that the ranking obtained for the temperature balance differs significantly, as the surface heat flux is responsible for almost half of the variations 5 (44\%), while horizontal advection and vertical entrainment exhibit closer contributions (29\% and $24 \%$, respectively).

The salinity variability arising from the combination of these processes is confronted to the WOA 2001 in situ climatology. The seasonal variability distribution is well reproduced in the model, even if its amplitude is systematically higher in the simulation, 10 due to its daily forcing and its finer effective resolution. The simulation also enables to investigate the salinity variability at daily frequency, which can not be assessed from the monthly climatology. Daily fluctuations are high mainly over areas characterised by a strong seasonal cycle, but their distribution is significantly different. In particular, the daily variability is higher within the midlatitudes currents than in tropical regions, in

15 contrast with the seasonal variability. The annual mean salinity is used for detecting areas where the model behaviour is inconsistent with the climatology. The simulation retains salinity extrema reasonably well, even if their shapes and locations are slightly modified. In particular, the model tends to enhance the maximum values and to shift them either toward the equator or toward the coast. The model generally enhances the

horizontal gradients in comparison with the observed fields and generates some local extrema which are not found in the climatology.

\subsection{Discussion}

The examination of the salinity monthly variability and annual mean reveals some simulation defects:

25 In inter-tropical areas, the simulated salinity is too low because of overestimated precipitations in the ECMWF model, caused. by too strong atmospheric convection over ITCZs. As the mixed layer is particularly thin, the surface water is considerably freshened. Some ocean modellers have chosen to reduce these tropical precipitations
OSD

4, 41-106, 2007

SSS variability from a global MLM

S. Michel et al.

Title Page

Abstract Introduction

Conclusions References

Tables Figures

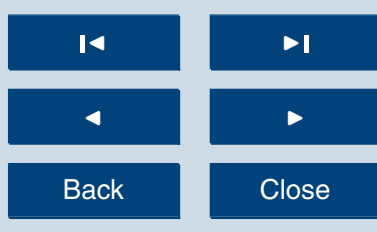

Full Screen / Esc

Printer-friendly Version

Interactive Discussion

EGU 
by up to $30 \%$. Alternatively, rain estimates from satellite micro-wave remote sensing could provide a more reliable freshwater forcing.

In the vicinity of the equator, the simulated salinity exhibits zonal structures inconsistent with observations. This is caused by the Ekman terms removal in the $3^{\circ} \mathrm{S}-3^{\circ} \mathrm{N}$ 5 band. However, the Ekman terms continuity can be ensured by using a $\beta$-plane approximation, equivalent to using a complex friction coefficient (Lagerloef et al., 1999). Thus, Ekman transport switches gradually from a right-wind direction away from the equatorial band to a downwind direction at the equator.

Within the strongest currents, such as the Gulf Stream, the Kuroshio and the AACC, 10 the simulated MLD and SSS present many small scale features, associated with very high variability. These artificial structures are due to inconsistencies between geostrophic currents and atmospheric fluxes. Indeed, the currents in these areas are characterized by intense mesoscale activity, associated with spatial scales down to $1 / 3^{\circ}$, while the atmospheric fields contain no scales smaller than $2-3^{\circ}$. Therefore, the 15 geostrophic currents transport fine scale anomalies which have no signature in the meteorological data (including the SST), then the model can not adjust properly the MLD evolution. Such inconsistencies would be reduced by using forcing fields for a particular year, rather than from a climatology. Additionally, to ensure that all input variables have similar spatial scales, satellite data could be used to estimate surface fluxes and SST at a finer resolution.

At subpolar latitudes, the simulated salinity drifts from the observations because of the sea-ice influence. During spring and summer, ice melting generates considerable amounts of freshwater which spread toward lower latitudes. This process is not properly accounted for in the model, which uses a salinity climatology as a boundary 25 condition. During autumn and winter the ocean surface experiments a very intense cooling, eventually leading to ice formation. The resulting stratification is so weak that even a slight modification in the surface forcing can result in a large deepening of the mixed layer. Both mechanisms contribute to overestimated salinity variability at high latitudes. This problem could be solved by using satellite observations to infer the ice

OSD

4, 41-106, 2007

SSS variability from a global MLM

S. Michel et al.

Title Page

Abstract Introduction

Conclusions References

Tables Figures

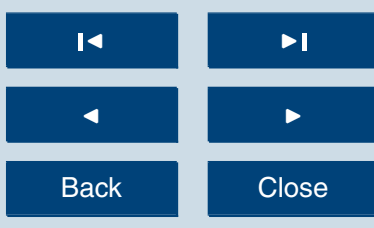

Full Screen / Esc

Printer-friendly Version

Interactive Discussion 
coverage and by improving the in situ vertical profiles in polar regions.

\subsection{Perspectives}

Many sensitivity studies can be conducted with this model, thanks to its low computational cost. In particular, the advection feedback effect should be investigated. In the 5 present simulation, the horizontal salinity gradients are computed from climatological fields. This "robust diagnostic" mode provides a stable simulation and is appropriate to study the salinity balance over the global domain. Alternatively, in the "full prognostic" mode, the gradients are computed from the simulated salinity fields. This mode allows studying anomalies growth or decay and their horizontal propagation, as in the analysis by Delcroix et al. (2005), based on in situ measurements over the tropical Atlantic and Pacific.

Some simulation inconsistencies are likely to be suppressed using interannual forcing fields instead of climatological fields, in particular for geostrophic currents and surface temperature. The local daily variability and the interannual variations of the salinity could then be validated against time-series at PIRATA and TAO moorings. At large scales, the salinity variability could be compared to objective analyses in the Atlantic performed by Reverdin et al. (2006). At global scale, the simulated long-term tendency could be compared to the estimates from Boyer et al. (2005). The results from this simple 2-D model should be compared to more sophisticated 3-D OGCMs, particularly those not using relaxation toward a climatological salinity.

Additionally, areas where the simulated SSS drifts systematically, while the SST is stable, reveal errors in the freshwater forcing. When a reliable global SSS estimate will be available (as expected from the SMOS satellite, to be launched by ESA in 2007), the model could be used to adjust freshwater fluxes to observed salinity variations. Such an inversion was performed for heat fluxes by Caniaux et al. (2005a) over a limited area in the North-East Atlantic, using a combination of in situ data and satellite SST measurements. The SMOS mission will infer SSS using a complex retrieval algorithm. The MLM could provide a salinity first guess for this algorithm, as well as upper and

4, 41-106, 2007

SSS variability from a global MLM

S. Michel et al.

\section{Title Page}

Abstract Introduction

Conclusions References

Tables Figures

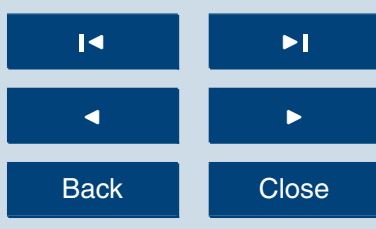

Full Screen / Esc

Printer-friendly Version

Interactive Discussion 
lower bounds for its results. Moreover, the model could be used to localize areas characterized by very high or low SSS variability, useful for the sensor calibration.

\section{Appendix A}

\section{Forcing data}

The model is run with a high-frequency climatological forcing, in order to focus on the variability at daily to seasonal scales. Thus a mean year must be computed for each of the input variables (see Table 1 for a summary of the input data characteristics). Heat, freshwater and momentum fluxes at the sea surface are obtained from the ERA40 reto 2002, but the period 1990-2002 was chosen to compute an annual time-series, because it benefits from a higher consistency and accuracy. Indeed, since the beginning of the 1990's, the model assimilates many satellite data, including sea surface wind speed and elevation, solar and thermal radiations. As several fluxes are strongly conparticular the wind stress and the radiative heat fluxes. Moreover, the meteorological model provides a set of fluxes which is more consistent than the individual estimates from various satellites.

The net heat flux entering the ocean surface is obtained by summing the radiative 20 and turbulent fluxes. The net radiative components consist in short-waves solar radiation and long-waves thermal radiation. The fraction of solar radiation which penetrates beneath the mixed layer is neglected. The turbulent components are the latent heat flux and the sensible heat flux. Both turbulent fluxes strongly depend on wind speed, so it is more accurate to use wind data from the same source. Turbulent fluxes, as well as thermal radiation, also depend on SST. Thus there can be strong feedbacks between atmospheric fluxes and upper ocean temperature. Ideally, heat forcing at the ocean surface should be modified according to the simulated temperature variations. As we

OSD

4, 41-106, 2007

SSS variability from a global MLM

S. Michel et al.

\section{Title Page}

Abstract Introduction

Conclusions References

Tables Figures

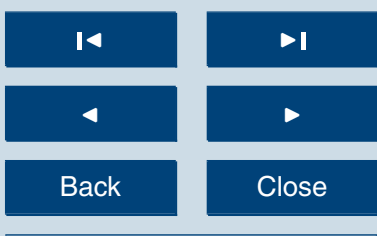

Full Screen / Esc

Printer-friendly Version

Interactive Discussion 
focus on the mixed layer salinity, our model assimilates the SST from the ECMWF reanalysis as an additional forcing field, thus no flux modification is required. Note that the ECMWF model uses a first guess of SST, which is set to the weekly analyses from Reynolds and Smith (1994), obtained from a combination of in situ and satellite mea5 surements. It was shown that the integrated SST fields remain very close to these initial values. Thus the SST input of our model is also close to up-to-date satellite estimates.

Salinity at the sea surface does not affect directly air-sea exchanges, so it can be treated as a passive variable. The net freshwater flux is obtained by subtracting the evaporation rate from the sum of precipitations and river runoffs. As the evaporation 10 rate is proportional to the latent heat flux, it is also strongly linked to wind speed. It shares the same origin, namely the ERA40 reanalysis. The precipitations rate can be considered as an independent parameter with respect to other fluxes. The rain outputs are known to be of poor quality in the ECMWF model (as in most global weather prediction systems), especially in tropical regions, because of persistent and unsolved prob15 precipitations fields are also used to force our simulations, as no significantly better estimate is available with a global coverage and a daily frequency. Finally, the river runoffs are extracted from the global climatology computed by Dai and Trenberth (2002), which gathers in situ data from hundreds of major rivers, integrated on $2^{\circ} \times 2^{\circ}$ grid and with a monthly frequency.

The geostrophic current is a crucial input variable in our model, as the mixed layer dynamics are imposed by the forcing (see Sect. 2.2). The best estimates of sea surface height (SSH) are obtained from space-borne altimetry, through the combination of measurements from several satellites with complementary orbits. Data from five recent

altimetry missions (TOPEX/Poseidon, ERS-2, GFO, ENVISAT and Jason-1), starting from August 2001, were combined and objectively analysed to produce gridded fields of sea level anomaly (SLA). A new estimate of the Earth's geoid (Rio and Hernandez, 2004), benefiting of an unprecedented precision, was added to the SLA fields to obtain total SSH. This dataset, built in the frame of the SSALTO-DUACS project, is delivered
OSD

4, 41-106, 2007

SSS variability from a global MLM

S. Michel et al.

\section{Title Page}

Abstract Introduction

Conclusions References

Tables Figures

I

14

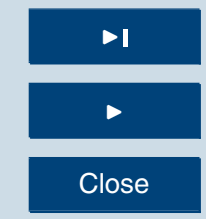

Back

Full Screen / Esc

Printer-friendly Version

Interactive Discussion 
with a $0.33^{\circ}$ resolution in both directions and a 3.5 day frequency. Its accuracy is estimated around $1 \mathrm{~cm}$, which makes it the most reliable SSH product available over the whole global ocean. The absolute geostrophic velocities were then computed through finite differencing of the SSH fields, using the classical geostrophy relation, as written 5 in Eq. (3). A particular treatment for low latitudes, based on the derivation of this equation in the meridional direction, allows the computation of velocities near the equator (Picaut and Tournier, 1991). The velocity divergence (not shown) presents no large scale and permanent structures, except in shallow areas and around islands. Thus the resulting circulation is essentially non-divergent, consistently with the geostrophic 10 equilibrium assumption.

The model also requires estimates of temperature $T_{d}$ and salinity $S_{d}$ within the deep layers, to compute the vertical gradients used in the entrainment term, computed from Eq. (4). The accuracy of these parameters is less important than for the forcing variables, as only the differences from the mixed layer values $\left(T-T_{d}\right)$ and $\left(S-S_{d}\right)$ are used. 15 Nonetheless, better results are obtained using realistic profiles than using a constant average profile. A monthly climatology is used to constrain the seasonal evolution of the deep layer properties at each point of the global domain. The World Ocean Atlas 2001 (hereafter WOA01) was chosen, because it was built from numerous in situ measurements, leading to acceptable uncertainties, even for salinity in the most sparely 20

\section{sampled areas. Other advantages of this climatology lie in its horizontal resolution,} similar to the ECMWF forcing fields ( $1^{\circ}$ in both directions) and its vertical resolution which is enhanced near the surface (with a level spacing from 10 to $100 \mathrm{~m}$ ). The SSS values from this climatology are also used to initialize the salinity of the mixed layer model. The initial temperature field is set to the SST from the ERA40 reanalysis, to averages from ERA40 and WOA01 (not shown) exhibit only small scale features, with mean biases lower than $0.5^{\circ} \mathrm{C}$.

A simulation using a fully climatological forcing dataset was conducted, to assess the model ability to reproduce the seasonal evolution of the mixed layer. The air-sea fluxes

OSD

4, 41-106, 2007

SSS variability from a global MLM

S. Michel et al.

Title Page

Abstract Introduction

Conclusions References

Tables Figures

I

14

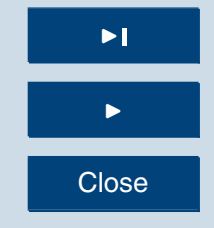

Full Screen / Esc

Printer-friendly Version

Interactive Discussion 
from the ECMWF model, originally cumulated during 6-hour periods, were integrated daily. Then each set of 12 daily values from the 1990-2001 series was averaged to obtain daily climatological values. The geostrophic velocities, originally provided with a weekly, then twice-weekly frequency, were first interpolated daily during the series 5 from 22 August 2001 to 21 August 2005. Then each set of 4 daily values was averaged, similarly to the meteorological variables, but over a shorter, though significant period. Finally, the velocities were interpolated onto the ECMWF model grid, using a $3 \times 3$ points averaging scheme which smoothes the current intensity, but preserves the volume transport in each mesh cell. The tri-dimensional temperature and salinity fields 10 from the WOA01 climatology were also projected on the ECMWF grid, using a different scheme based on a $2 \times 2$ points interpolation, in order to preserve the horizontal gradients which are crucial for the advection terms.

\section{Appendix B}

15 Inversion method

In Eq. (1) governing the mixed layer temperature, if $T$ is considered as an input parameter, $h$ might be obtained through a direct calculation:

$h=\frac{Q_{\text {net }} /\left(C_{p} \rho_{o}\right)-U_{E} \cdot \nabla^{T}-\Gamma\left(w_{e}\right)\left(T-T_{d}\right)}{\partial_{T} h+u_{g} \cdot \nabla^{T}-k \nabla^{2} T}$

where $\boldsymbol{U}_{E}$ is the (depth-independent) Ekman transport, expressed from Eq. (3):

20 $\boldsymbol{U}_{E}=\delta_{x} h \boldsymbol{u}_{E}=\frac{\delta_{x}}{\rho f} \boldsymbol{\tau} \times \boldsymbol{k}$

with $\delta_{x}$ the width of a grid cell. However, as the entrainment velocity $w_{e}$ and the temperature of the deep layer $T_{d}$ also depends on $h$ in Eq. (4), the inversion is not straightforward. Note that both upper and lower terms in Eq. (A1) can be either positive or
OSD

4, 41-106, 2007

SSS variability from a global MLM

S. Michel et al.

\section{Title Page}

\section{Abstract}

Introduction

Conclusions

References

Tables

Figures

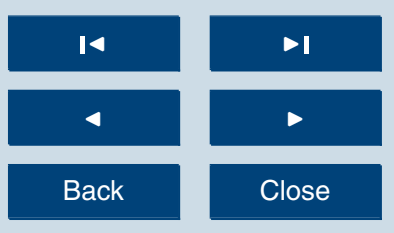

Full Screen / Esc

Printer-friendly Version

Interactive Discussion 
negative, thus a priori nothing ensures that the resulting depth is positive. Moreover, if the components in the upper (lower) term almost cancel each other, the result can reach very low (large) values, violating the continuous nature of the mixed layer depth.

Therefore, two different situations must be considered: if the mixed layer is in de5 trainment phase $\left(w_{e}<0\right)$, the vertical entrainment term is cancelled and Eq. (A1) simply writes:

$h_{\mathrm{det}}=\frac{Q_{\mathrm{net}} /\left(C_{p} \rho_{0}\right)-U_{E} \cdot \nabla T}{\partial_{t} T+u_{g} \cdot \nabla T-\kappa \nabla^{2} T}$

Alternatively, in case of entrainment $\left(w_{e}>0\right)$, Eq. (A1) becomes:

$h\left(\partial_{t} T+u_{g} \cdot \nabla T-k \nabla^{2} T\right)=\frac{Q_{\text {net }}}{C_{p} \rho_{0}}-U_{E} \cdot \nabla T-\left(w_{E}+\partial_{t} h\right)\left(T-T_{d}(h)\right)$

10 This formula leads to a non-linear differential equation in $h$, which cannot be solved exactly. Thus it must be solved numerically, using a time-integration. A semi-implicit scheme is necessary, in order to adjust simultaneously the depth value $h$, its temporal variation $\partial_{t} h$ and the corresponding temperature $T_{d}$. This is performed through a minimization technique, which fits the model temperature $T$ to the input SST. In particular situations, this method can lead to two different minima for the temperature error. The algorithm selects the shallowest error minimum, in order to capture the upper layer base (seasonal thermocline), rather than a deeper layer (main thermocline) which would not be in phase with the SST evolution.

In case of detrainment, because of the unstable nature of Eq. (A3), $h$ is very sensitive to errors and inconsistencies between the various parameters. Thus the resulting depth can reach arbitrarily high or low values. Meanwhile, in the real ocean, the mixed layer can not shoal to the surface because of wind induced turbulence. The lower bound of MLD is set to a mixing length, which characterizes the equilibrium between stabilization by air-sea fluxes and mixing by wind friction (Phillips, 1969). This length
OSD

4, 41-106, 2007

SSS variability from a global MLM

S. Michel et al.

Title Page

Abstract Introduction

Conclusions

References

Tables

Figures

I

14

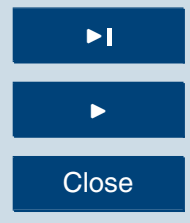

Back

Full Screen / Esc

Printer-friendly Version

Interactive Discussion 
can be computed from the classical formulation for the buoyancy flux at the surface:

$N(0)=g\left(\frac{\alpha Q_{n e t}}{C_{p} \rho_{0}}-\beta(E-P-R) S\right)=\frac{K}{L_{b}}\left(\frac{\tau}{\rho}\right)^{\frac{3}{2}}$

OSD

where $\alpha=2 \times 10^{-4} \mathrm{~K}^{-1}$ and $\beta=1 \times 10^{-3} \mathrm{psu}^{-1}$ are the seawater thermal expansion and haline contraction coefficients, respectively, $\mathrm{K}=0.42$ is the Karman constant, and $L_{b}$ is 5 the Monin-Obukhov length. Therefore, if the computation indicates that the mixed layer is detrained, the value of $h$ resulting from Eq. (A3) is bounded by $L_{b}$ from Eq. (A5): $h$ $=\max \left(\mathrm{h}_{\mathrm{det}}, L_{b}\right)$.

Two other adjustments are applied in case of detrainment. Excessively high values are removed by selecting only the results which correspond to effective detrainment $10\left(w_{e}<0\right)$ and to a positive depth $(h>0)$. Finally, $h$ is relaxed toward the computed value: $\mathrm{h}(\mathrm{t})=\mathrm{h}(\mathrm{t}-1)+\left(\mathrm{h}_{\text {det }}-\mathrm{h}(\mathrm{t}-1)\right) \delta \mathrm{t} / \Delta \mathrm{t}$, using a time-scale $\Delta \mathrm{t}=1$ month. Thus, the mixed layer is not allowed to adjust instantaneously to stabilising fluxes, but shoals progressively to its equilibrium depth, as observed in the real ocean (Gaillard et al., 2005).

As a first step, this algorithm requires determining whether the mixed layer is shoal15 ing or deepening, to decide which of Eqs. (A3) or (A4) shall be used. For this purpose, both entrainment and detrainment computations are performed, then the algorithm retains the $h$ value which leads to the best agreement with the SST input. This way, the algorithm selects objectively the more physically consistent solution, without any empirical stability criterion. In cases where no entrainment depth leads to an error 20 minimum and the detrainment depth $h_{\text {det }}$ is negative, $h$ is set according to its long-term persistence (with a time scale equal to $\Delta t$ ). Over the global domain, such situations arise during less than $20 \%$ of the time-series, thus the algorithm converges in more than $80 \%$ of cases.

This simple minimisation technique relies on very few parameters. The only 25 necessary parameters are the step $\Delta h$ for depth scanning in case of entrainment, or the relaxation time-scale $\Delta t$ in case of detrainment. Sensitivity tests show that the computation stability and the seasonal evolution of $h$ are weakly sensible to both

4, 41-106, 2007

SSS variability from a global MLM

S. Michel et al.

Title Page

Abstract Introduction

Conclusions

References

Tables

Figures

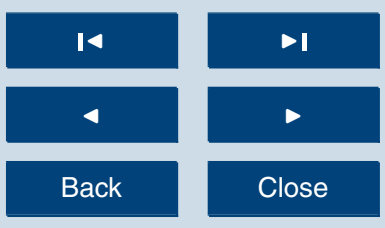

Full Screen / Esc

Printer-friendly Version

Interactive Discussion 
values (for $\Delta h=0.1$ to $1.0 \mathrm{~m}$ and $\Delta t=7$ days to 3 months). As a result, this algorithm provides an MLD estimate which is consistent with the all the forcing fluxes and the input surface variables (SST and surface currents), without using any arbitrary criterion.

Acknowledgements. The authors would like to acknowledge the National Oceanographic Data Center for the WOA climatology (http://www.nodc.noaa.gov/OC5/WOA01), the European Center for Medium-range Weather Forecast and Meteo France for providing the ERA40 reanalysis 10 (http://data.ecmwf.int/data) and the AVISO center for the SSALTO-DUACS Absolute Dynamic Topography (http://www.jason.oceanobs.com/html/donnees/duacs). We thank C. De BoyerMontégut for kindly sharing his mixed layer depth climatologies (http://www.lodyc.jussieu.fr/ $\sim$ cdblod/mld.html). We are particularly grateful to G. Reverdin for providing many helpful remarks. This work was funded by a Ph.D. grant from IFREMER and CNES, as a contribution to the European Space Agency's SMOS project.

\section{References}

Alexander, M. A., Scott, J. D., and Deser, C.: Processes that influence sea surface temperature and ocean mixed layer depth variability in a coupled model, J. Geophys. Res., 105(C7), 16 823-16 842, 2000.

Boyer, T. P., Levitus, S., Garcia, H. E., Locamini, R. A., Stephens, C., and Antonov, J.: Objective analyses of annual, seasonal, and monthly temperature and salinity for the world ocean on a 0.25 degrees grid, Int. J. Climatol., 25(7), 931-945, 2004.

Boyer, T. P., Levitus, S., Antonov, J. I., Locamini, R. A., and Garcia, H. E.: Linear trends in salinity for the World Ocean, 1955-1998, Geophys. Res. Letters, 32(1), L01604, 2005.

25 Caniaux, G., Brut, A., Bourras, D., Giordani, H., Paci, A. ,Prieur, L., and Reverdin, G.: A 1 year sea surface heat budget in the northeastern Atlantic basin during POMME experiment: 1. Flux estimates, J. Geophys. Res., 110, C07S02, 2005a.

Caniaux, G., Brut, A., Bourras, D., Giordani, H., Paci, A., Prieur, L., and Reverdin, G.: A 1 year sea surface heat budget in the northeastern Atlantic basin during POMME experiment: 2 .

Flux optimization, J. Geophys. Res., 110, C07S03, 2005b.
SSS variability from a global MLM

S. Michel et al.

\section{Title Page}

Abstract Introduction

Conclusions

References

Tables

Figures

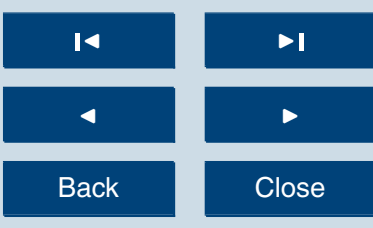

Full Screen / Esc

Printer-friendly Version

Interactive Discussion 
Dai A., and Trenberth, E.: Estimates of freshwater discharge from continents: latitudinal and seasonal variations, J. Hydrometeorol., 3(6), 660-687, 2002.

De Boyer-Montégut, C., Madec, G., Fischer, A. S., Lazar, A., and ludicone, D.: Mixed layer depth over the global ocean: An examination of profile data and a profile-based climatology,

5 J. Geophys. Res., 109 (C12), 52-71, 2004.

Delcroix, T., Dessier, A., Gourriou, Y., and McPhaden, M.: Time and space scales for sea surface salinity in the tropical oceans, Deep Sea Res., 52(5), 787-813, 2005.

Dickson, B., Yashayaev, I., Meincke, J., Turrell, B., Dye, S., and Holfort, J.: Rapid freshening of the deep North Atlantic Ocean over the past four decades, Nature, 416(6883), 832-837, 102002.

Frankignoul, C. and Hasselmann, K.: Stochastic climate models, Part II: application to seasurface temperature anomalies and thermocline variability, Tellus, 29, 289-305, 1977.

Gaillard, F., Mercier H., and Kermabon, C.: A synthesis of POMME physical data set: one year monitoring of the upper layer, J. Geophys. Res., 110, C07S07, 2005.

Giordani, H., Caniaux, G., and Prieur, L.: A simplified 3-D oceanic model assimilating geostrophic currents: Application to the POMME experiment, J. Phys. Ocean., 35(5), 628644, 2005a.

Giordani, H., Caniaux, G., Prieur, L., Paci, A., and Giraud, S.: A 1 year mesoscale simulation of the northeast Atlantic: mixed layer heat and mass budgets during the POMME experiment,

20 J. Geophys. Res., 110, C07S08, 2005b.

Herterich,K. and Hasselmann, K.: Extraction of mixed layer advection velocities, diffusion coefficients, feedback factors and atmospheric forcing parameters from the statistical analysis of North Pacific SST anomaly fields, J. Phys. Ocean., 17, 2145-2156, 1987.

Holt, J. T. and James, I. D.: An s-coordinate density evolving model of the northwest European

25 continental shelf - 1, Model description and density structure, J. Geophys. Res., 106 (C7), 14 015-14 034, 2001.

Kitaigorodskii, S. A.: The physics of air-sea interaction. Chapter 12: The upper quasihomogenous layer and the seasonal thermocline in the open ocean, Israel program for scientific translations, ed. P. Greenberg, 204-221, 1973.

30 Kudryavtsev, V. N. and Soloviev, A. V.: Slippery near-surface layer of the ocean arising due to daytime dolar deating, J. Phys. Ocean., 20, 617-628, 1990.

Lagerloef, G. S. E., Mitchum, G. T., Lukas, R. B., and Niiler, P. P.: Tropical Pacific nearsurface currents estimated from altimeter, wind, and drifter data, J. Geophys. Res., 104

\section{OSD}

4, 41-106, 2007

SSS variability from a global MLM

S. Michel et al.

\section{Title Page}

Abstract Introduction

Conclusions References

Tables Figures

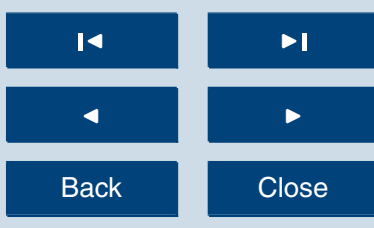

Full Screen / Esc

Printer-friendly Version

Interactive Discussion 
(C10), 23313-23 326, 1999.

Lagerloef, G. S. E.: Introduction to the special section: The role of surface salinity on upper ocean dynamics, air-sea interaction and climate, J. Geophys. Res., 107 (C12), 8000, 2002.

Le Cann, B., Assenbaum, M., Gascard, J. C., and Reverdin, G.: Observed mean and 5 mesoscale upper ocean circulation in the midlatitude northeast Atlantic, J. Geophys. Res., 110, C07S05, 2005.

Paiva, A. and Chassignet, E.: The impact of surface flux parameterizations on the modelling of the North Atlantic Ocean, J. Phys. Ocean., 31, 1860-1879, 2000.

Phillips, O. M.: The Dynamics of the Upper Ocean. Chapter 6.6: Turbulence in the surface layer, ed. Cambridge University Press, 281-295, 1969.

Picaut, J. and Tournier, R.: Monitoring the 1979-1985 equatorial pacific current transports with expendable bathythermograph data, J. Geophys. Res., 96 (supplement), 3263-3277, 1991.

Qiu, B. and Kelly, K. A.: Upper-ocean heat balance in the Kuroshio extension region, J. Phys. Ocean., 23, 2027-2041, 1993.

Reverdin, G., Kestenare, E., Frankignoul, C., and Delcroix, T.: Surface salinity in the Atlantic Ocean $\left(30^{\circ} \mathrm{S}-50^{\circ} \mathrm{N}\right)$, Prog. Ocean., in press, 2006.

Reynolds, R. W. and Smith, T. M.: Improved global sea surface temperature analyses using optimum interpolation, J. Clim., 7(9), 929-948, 1994.

Rio, M. H. and Hernandez, F.: A mean dynamic topography computed over the world ocean 41, C12032, 2004.

OSD

4, 41-106, 2007

SSS variability from a global MLM

S. Michel et al.

\section{Title Page}

Abstract Introduction

Conclusions

References

Tables

Figures

14

$\Delta$

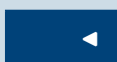

4

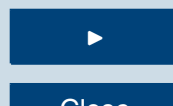

Back

Close

Full Screen / Esc

Printer-friendly Version

Interactive Discussion 


\section{SSS variability from a} global MLM

\section{S. Michel et al.}

Table 1. Original characteristics of the input datasets used in the simulation, with the same notations as in Eqs. (1) and (2). All these data were interpolated onto the ECMWF grid and converted temporally into daily climatologies.

\begin{tabular}{lllll}
\hline Variable & Source & Period & Frequency & Resolution \\
\hline$\tau_{x}, \tau_{y}, \mathrm{Q}_{\text {net }}, \mathrm{E}-\mathrm{P}, \mathrm{SST}$ & ECMWF ERA40 & Jan. 1990-Aug. 2002 & $6 \mathrm{~h}$ & $1.125^{\circ} \times 1.125^{\circ}$ \\
$\mathrm{R}$ & Dai \& Trenberth & climatology & 1 month & $2^{\circ} \times 2^{\circ}$ \\
$\mathrm{u}_{g}, \mathrm{v}_{g}$ & SSALTO-DUACS & Aug. 2001-Aug. 2005 & 3.5 day & $0.33^{\circ} \times 0.33^{\circ}$ \\
$\mathrm{T}_{d}(\mathrm{z}), \mathrm{S}_{d}(\mathrm{z})$ & WOA 2001 & climatology & 1 month & $1^{\circ} \times 1^{\circ}$ \\
\hline
\end{tabular}

\section{Title Page}

Abstract

Conclusions

Tables

References

Figures

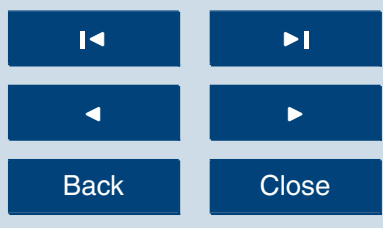

Full Screen / Esc

Printer-friendly Version

Interactive Discussion 
Table 2. Globally averaged contribution of each term of the salinity balance, in terms of mean value, mean amplitude (in $10^{-3}$ psu.day $^{-1}$ ) and local contribution (in \%). Subtotals are also indicated for the advection and entrainment terms. The averages are computed over the "icefree" domain, excluding the points where sea-ice is found on any day during the year. The mean local contribution is obtained by averaging the relative contribution $c_{i}$, defined in Eq. (5), over the global domain $\left(1 /\left(n_{x} n_{y}\right) \quad \Sigma_{x} \Sigma_{y} c_{i}(x, y), \mathrm{i}=1, \ldots, 6\right)$. Thus, it differs from the global

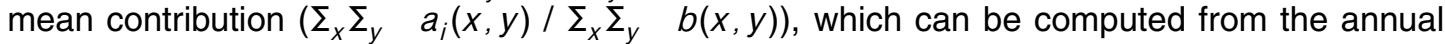
amplitudes.

\begin{tabular}{llll}
\hline Salinity balance term & $\begin{array}{l}\text { Annual mean } \\
\left(10^{-3} \mathrm{psu} / \text { day }\right)\end{array}$ & $\begin{array}{l}\text { Annual amplitude } \\
\left(10^{-3} \mathrm{psu} / \text { day }\right)\end{array}$ & $\begin{array}{l}\text { Local contribution } \\
(\%)\end{array}$ \\
\hline Ekman advection $(\mathrm{Ae})$ & -0.72 & 2.12 & 13.1 \\
Geostrophic advection $(\mathrm{Ag})$ & -0.23 & 4.08 & 32.5 \\
Total advection $(\mathrm{A}=\mathrm{Ae}+\mathrm{Ag})$ & -0.95 & 3.73 & 45.5 \\
Ekman pumping $(\mathrm{Be})$ & +0.33 & 0.59 & 2.5 \\
Diapycnal mixing $(\mathrm{Bd})$ & +1.48 & 2.15 & 21.7 \\
Total entrainment $(\mathrm{B}=\mathrm{Be}+\mathrm{Bd})$ & +1.82 & 2.45 & 24.2 \\
Air-sea flux $(\mathrm{C})$ & -1.89 & 3.31 & 22.2 \\
Lateral diffusion $(\mathrm{D})$ & -0.028 & 0.88 & 8.0 \\
Total tendency $(\mathrm{T}=\mathrm{A}+\mathrm{B}+\mathrm{C}+\mathrm{D})$ & -1.05 & 8.05 & 57.9 \\
Total amplitude $(\mathrm{S}=|\mathrm{A}|+|\mathrm{B}|+|\mathrm{C}|+|\mathrm{D}|)$ & & 13.13 & 100.0 \\
\hline
\end{tabular}

SSS variability from a global MLM

S. Michel et al.

\section{Title Page}

\section{Abstract}

Introduction

Conclusions

References

Tables

Figures

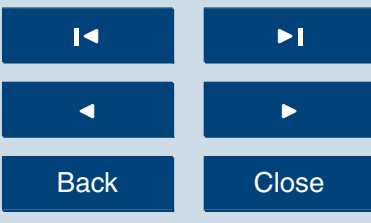

Full Screen / Esc

Printer-friendly Version

Interactive Discussion 


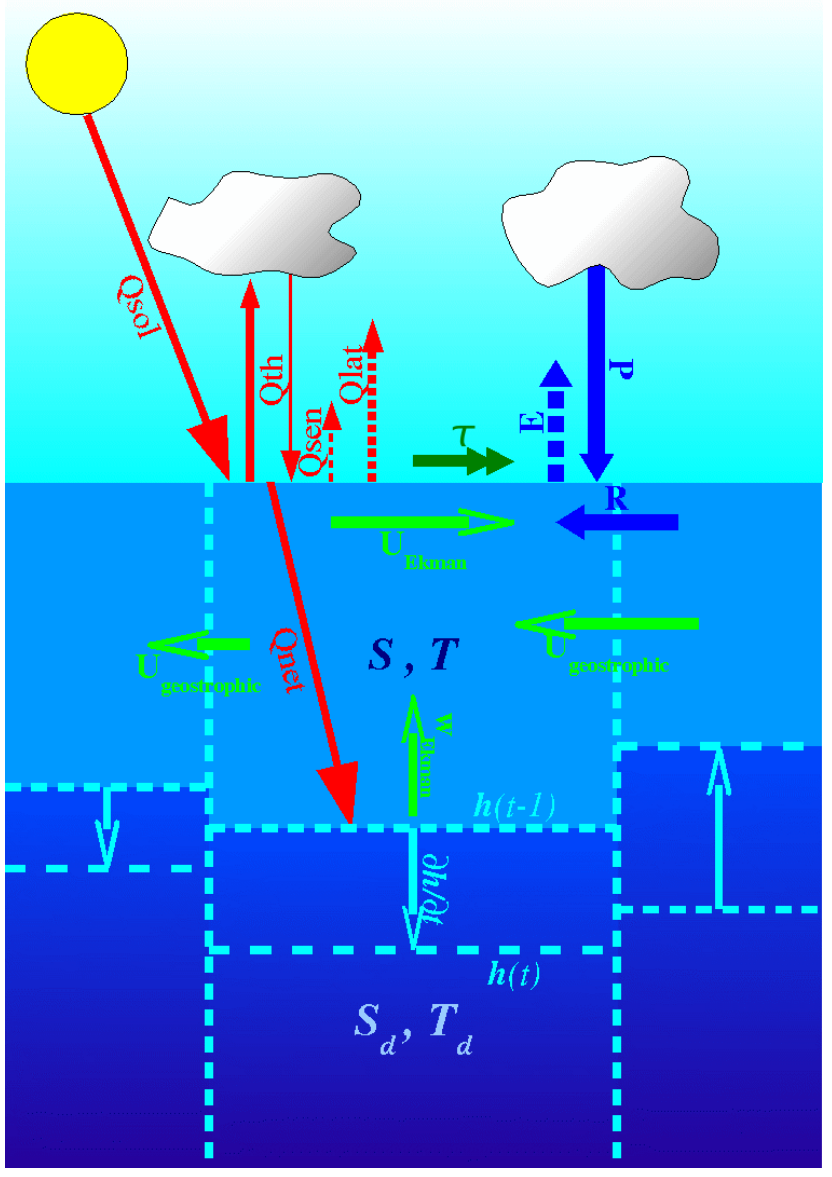

OSD

4, 41-106, 2007

SSS variability from a global MLM

S. Michel et al.

Title Page

\section{Abstract}

Conclusions

Tables

14

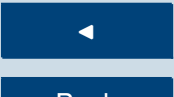

Back

Introduction

References

\section{Figures}

$\Delta$

$>$

Close

Full Screen / Esc

Printer-friendly Version

Interactive Discussion

Fig. 1. Schematic of the slab mixed layer model, for a given horizontal grid cell. The notations are the same as in the text (Sect. 2.1). Red arrows represent the components of the surface heat flux, blue arrows the surface freshwater fluxes, green arrows the wind stress and the horizontal and vertical currents. 
OSD

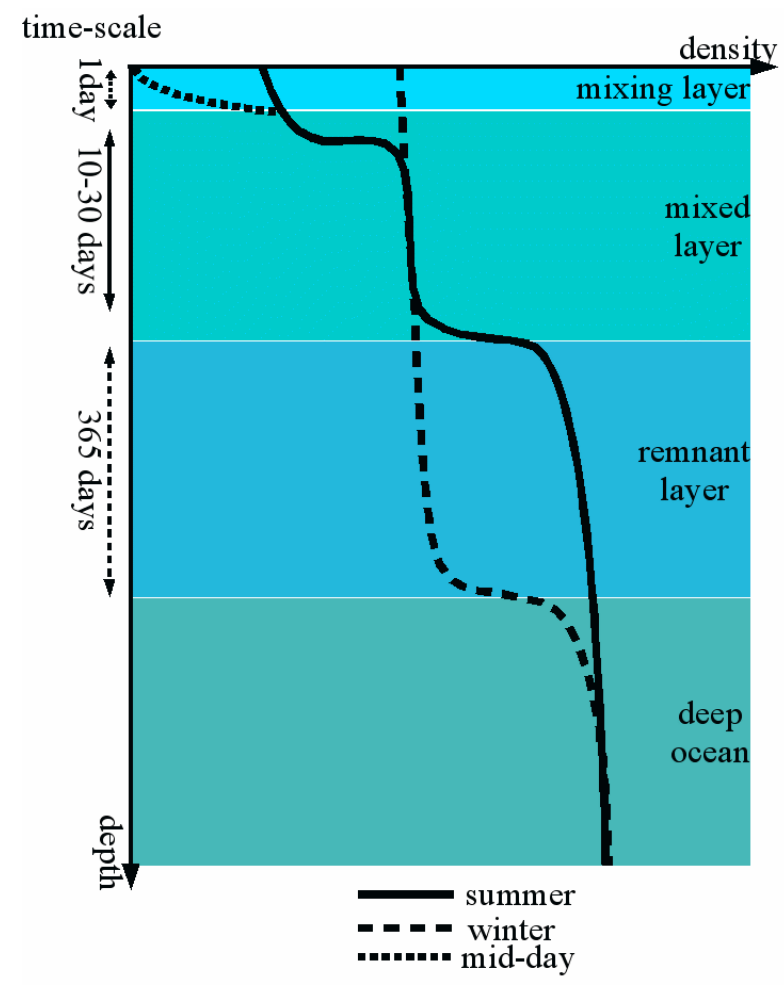

Fig. 2. Schematic of the various mixed layers, in terms of density, as a function of depth and characteristic time scale.
4, 41-106, 2007

SSS variability from a global MLM

S. Michel et al.

Title Page

\begin{tabular}{|c|c|}
\hline Abstract & Introduction \\
\hline Conclusions & References \\
\hline Tables & Figures \\
\hline & \\
\hline I4 & $\triangleright \mathbf{I}$ \\
\hline 4 & $\triangleright$ \\
\hline Back & Close \\
\hline Full Screen / Esc \\
\hline
\end{tabular}

Printer-friendly Version

Interactive Discussion 


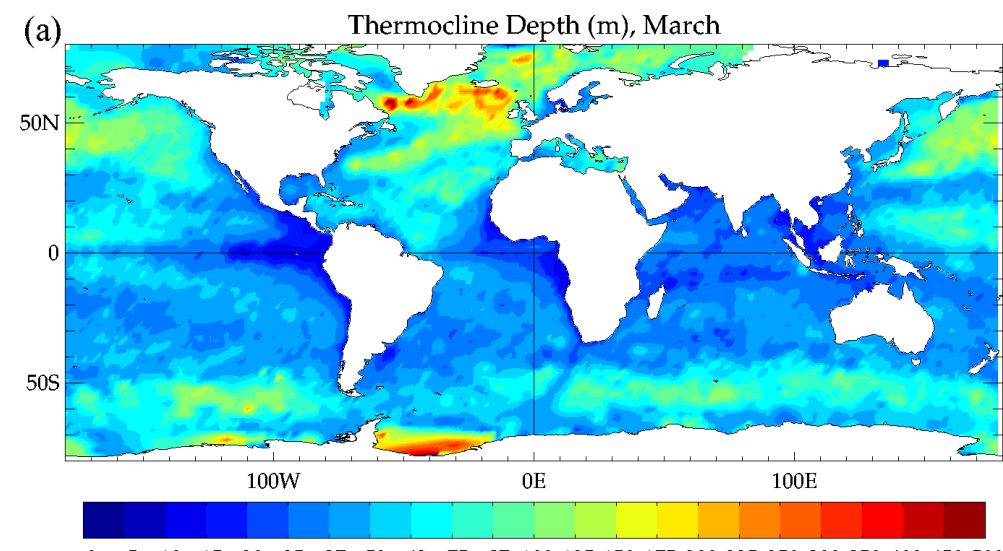

OSD

4, 41-106, 2007

SSS variability from a global MLM

S. Michel et al.

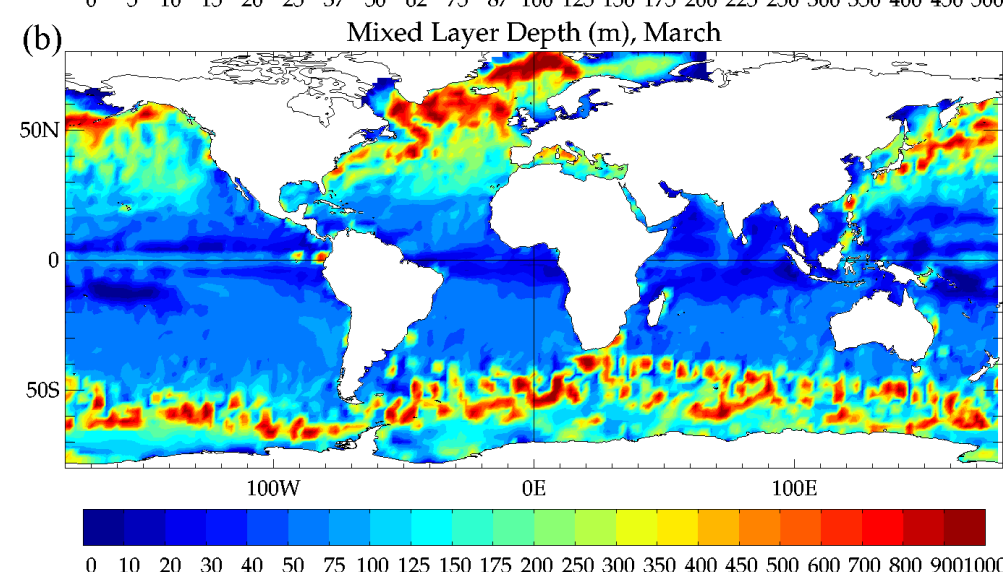

Title Page

Abstract

Introduction

Conclusions

References

Tables

Figures

14

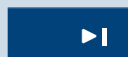

4

4

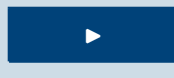

Back

Close

Full Screen / Esc

Printer-friendly Version

Interactive Discussion

EGU to $100 \mathrm{~m}$ fr $500<h<1000$. In the smoothed with a $3^{\circ} \times 3^{\circ}$ filter to be consistent with the resolution of the observed fields. 


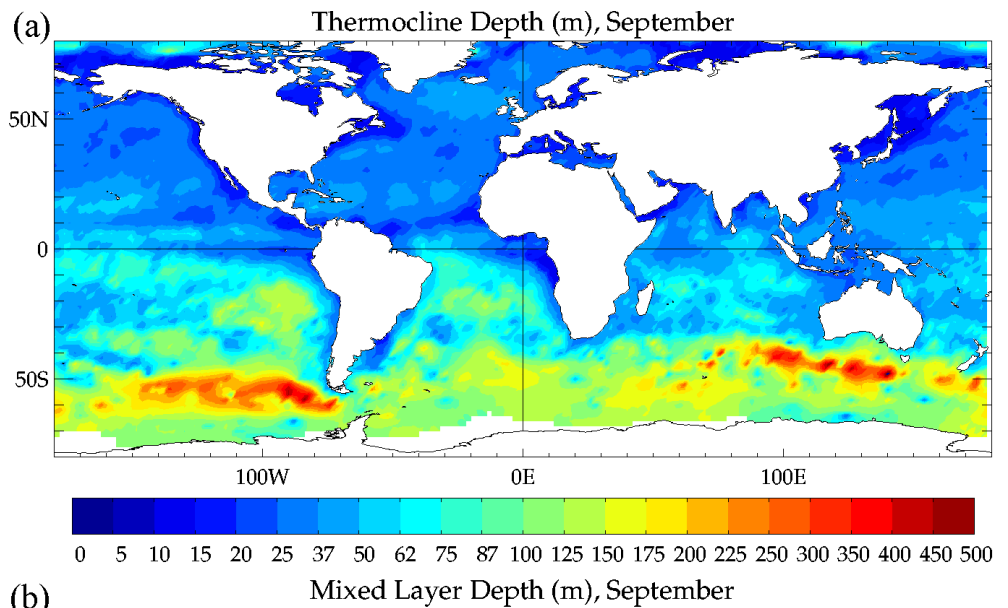

OSD

4, 41-106, 2007

SSS variability from a global MLM

S. Michel et al.

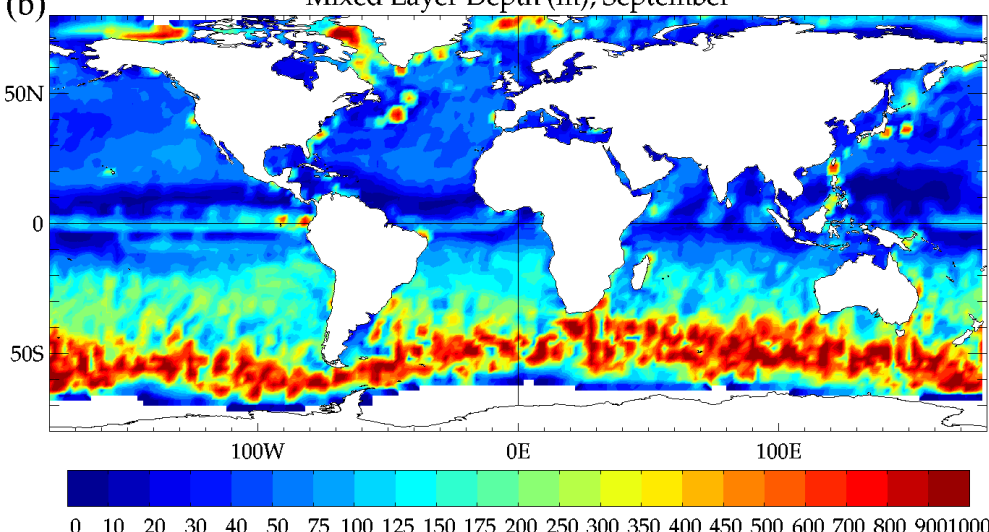

Abstract

Title Page

Introduction

Conclusions

References

Tables

Figures

14

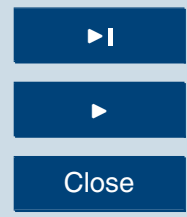

Back

Full Screen / Esc

Printer-friendly Version

Interactive Discussion

EGU 


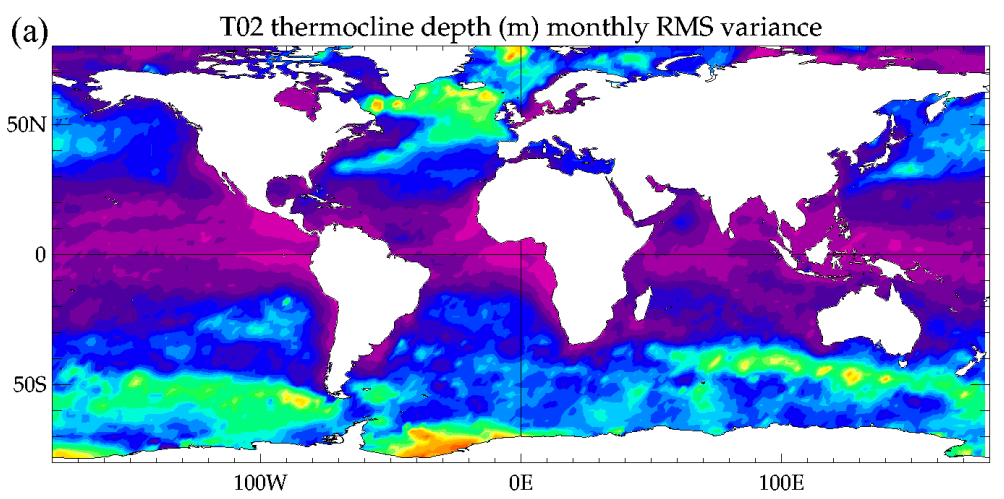

OSD

4, 41-106, 2007

SSS variability from a global MLM

S. Michel et al.

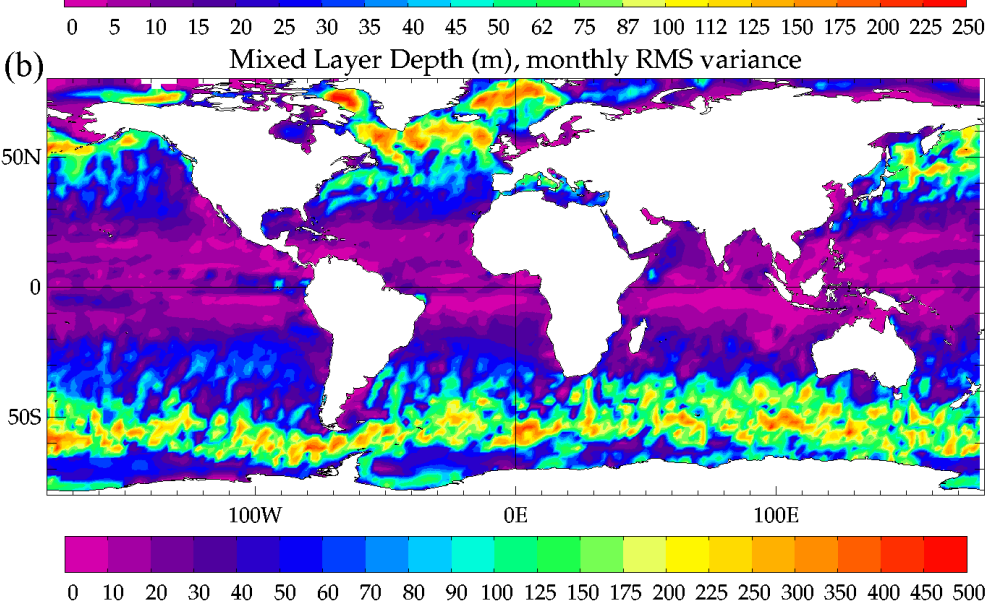

Title Page

Abstract

Introduction

Conclusions

References

Tables

Figures

14

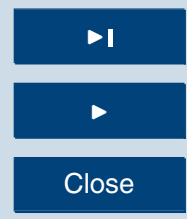

Back

Full Screen / Esc

Printer-friendly Version

Interactive Discussion

EGU 
OSD

4, 41-106, 2007

SSS variability from a global MLM

S. Michel et al.

Title Page

\section{Abstract}

Introduction

Conclusions

References

Tables

Figures

$50 \mathrm{~S}$
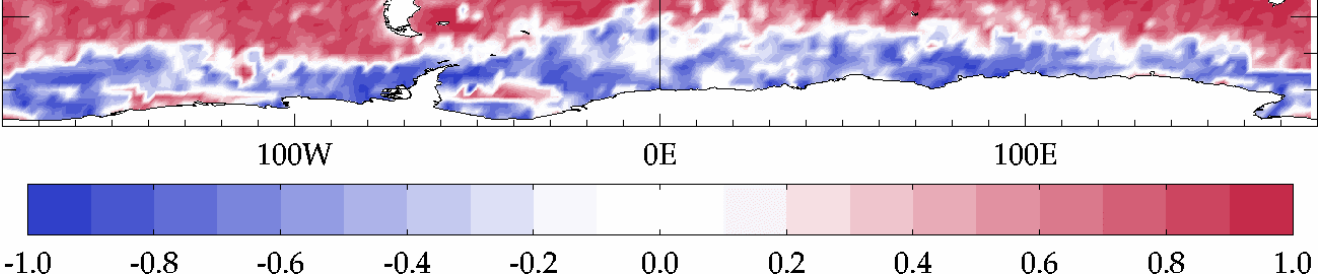

Fig. 6. Monthly correlation between the "T02" thermocline depth from De Boyer-Montégut et al. (2004) climatology and the mixed layer depth from the simulation.
.
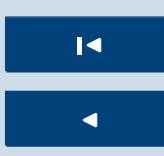

Back

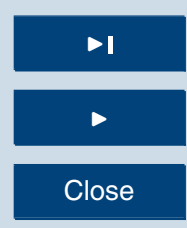

Full Screen / Esc

Printer-friendly Version

Interactive Discussion 
OSD

4, 41-106, 2007

SSS variability from a global MLM

S. Michel et al.

\section{Title Page}

Abstract

Introduction

Conclusions

References

Tables

Figures

$50 \mathrm{~S}$
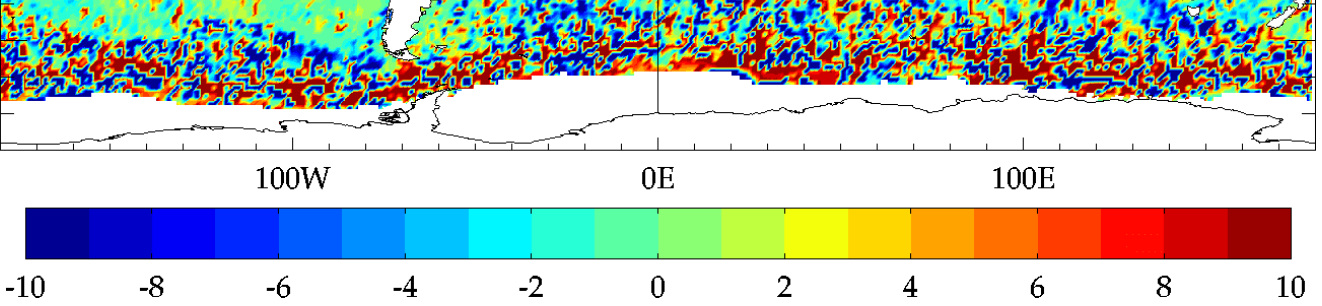

Fig. 7. Annual drift of the mixed layer depth (in $\mathrm{m} / \mathrm{year}$ ) from the simulation, computed as the difference between the final and initial fields: $d r i f t=h(31$ Dec. $)-h(1$ Jan. $)$.

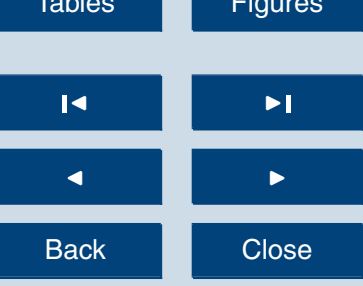

Full Screen / Esc

Printer-friendly Version

Interactive Discussion 
OSD

4, 41-106, 2007

SSS variability from a global MLM

S. Michel et al.

Title Page

Abstract

Introduction

Conclusions

References

Tables

Figures
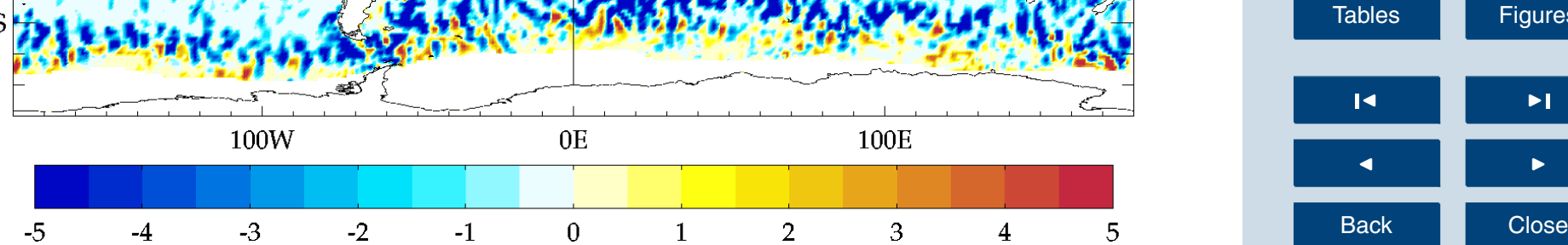

4

Back

$>$

Close

Full Screen / Esc

Printer-friendly Version

Interactive Discussion
Fig. 8. Annual mean of the mixed layer temperature error (in ${ }^{\circ} \mathrm{C}$ ) from the simulation, computed as the difference between the simulated temperature and the observed SST: error $(t)=T(t)-$ $S S T(t)$.
EGU 

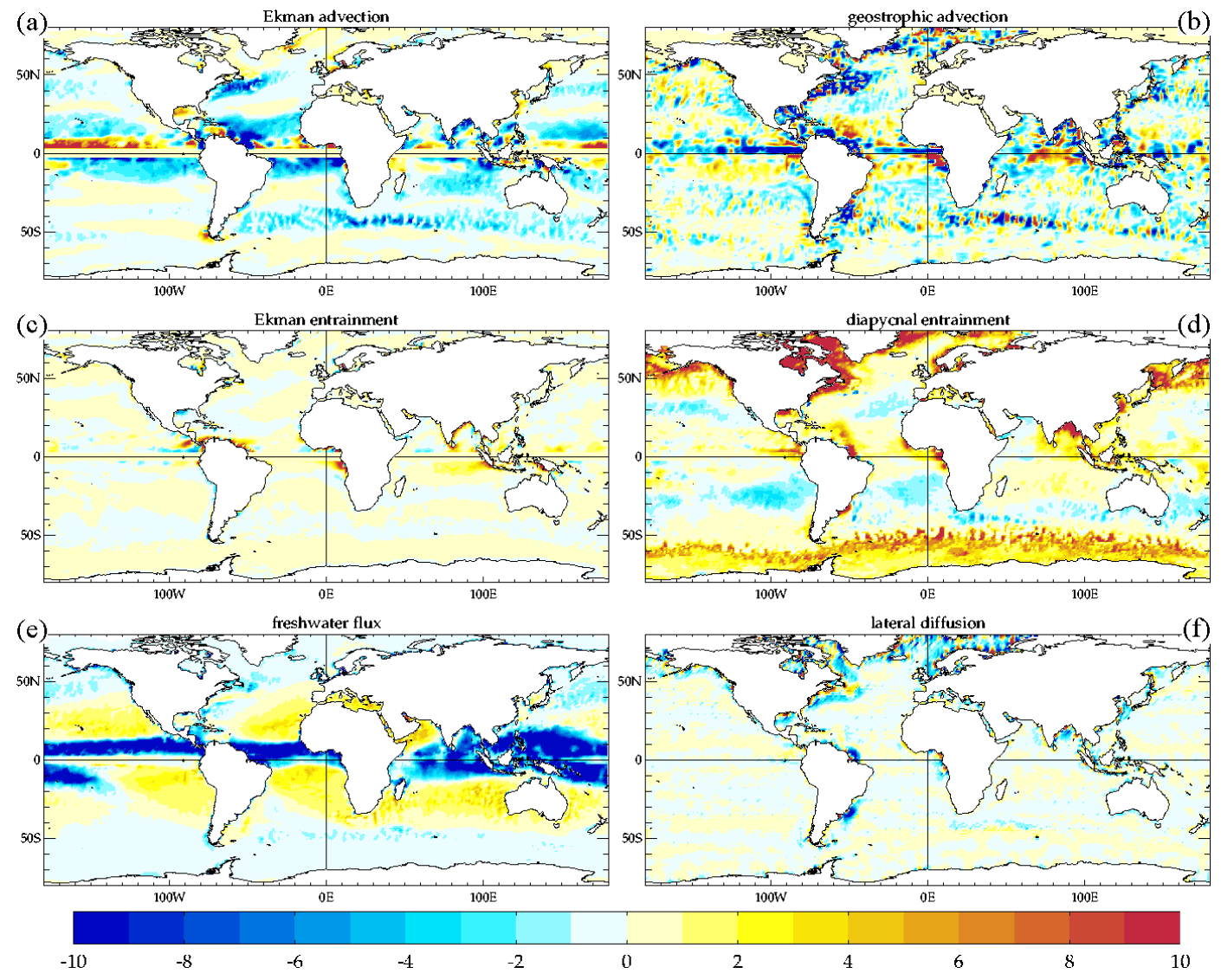

Fig. 9. Annual mean of the salinity balance terms (in $10^{-3}$ psu.day ${ }^{-1}$ ) from the simulation. (a) Ekman advection, (b) geostrophic advection, (c) Ekman entrainment, (d) diapycnal entrainment, (e) surface freshwater flux, (f) lateral diffusion. The colour scale is linear, with blue levels indicating an annual freshening $\left(\partial_{t} S<0\right)$ and red levels indicating an annual salinisation $\left(\partial_{t} S>\right.$ $0)$.

\section{OSD}

4, 41-106, 2007

SSS variability from a global MLM

S. Michel et al.

Title Page

\section{Abstract}

Introduction

Conclusions

References

Tables

Figures

14

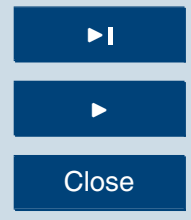

Back

Full Screen / Esc

Printer-friendly Version

Interactive Discussion

EGU 

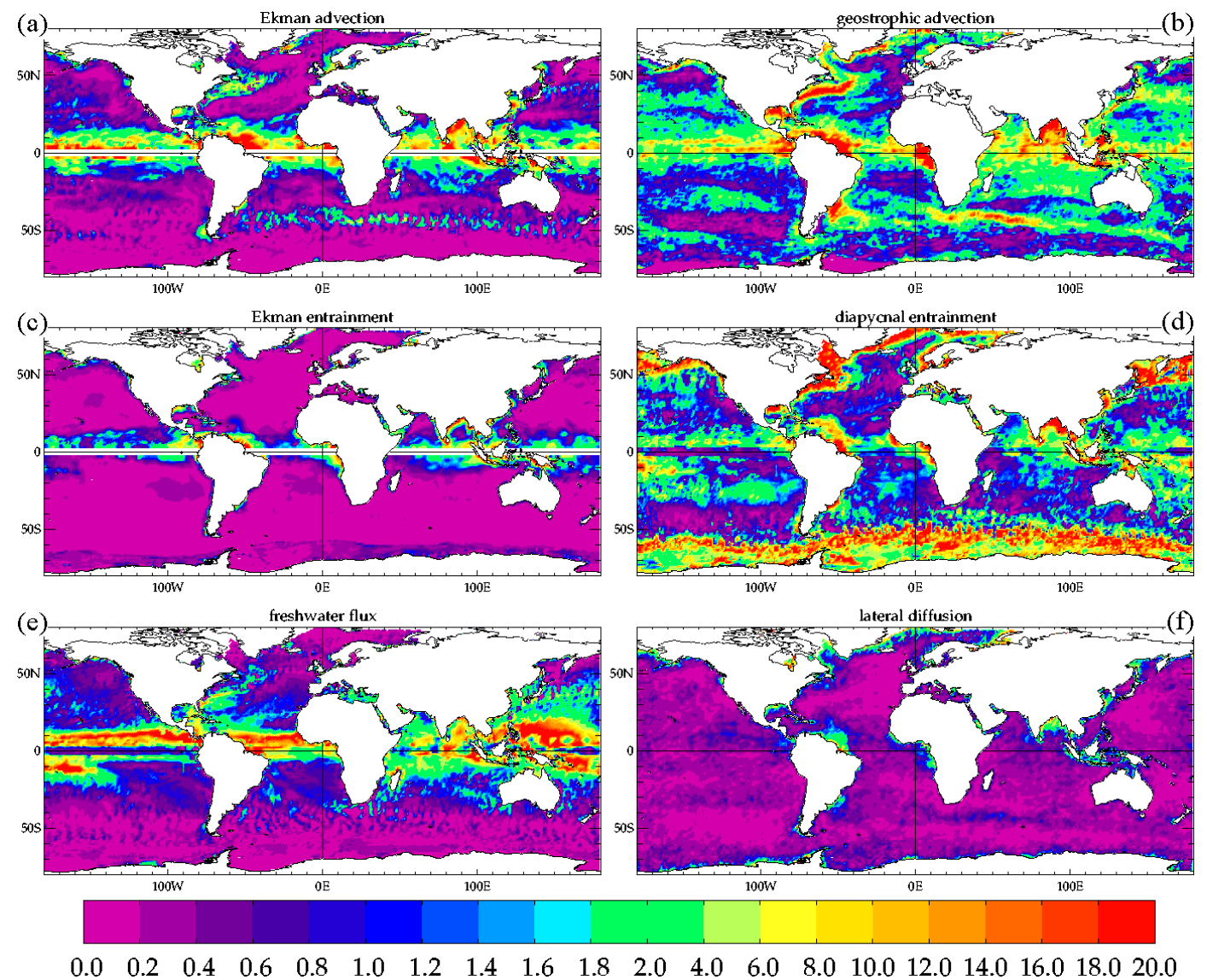

Fig. 10. Annual RMS of the daily values of the salinity balance terms (in $10^{-3}$ psu.day $^{-1}$ ) from the simulation. (a) Ekman advection, (b) geostrophic advection, (c) Ekman entrainment, (d) diapycnal entrainment, (e) surface freshwater flux, (f) lateral diffusion. The color scale is nonlinear, with intervals of 0.2 for $0<\partial_{t} S<2$ and 2.0 for $2<\partial_{t} S<20$.

\section{OSD}

4, 41-106, 2007

SSS variability from a global MLM

S. Michel et al.

Title Page

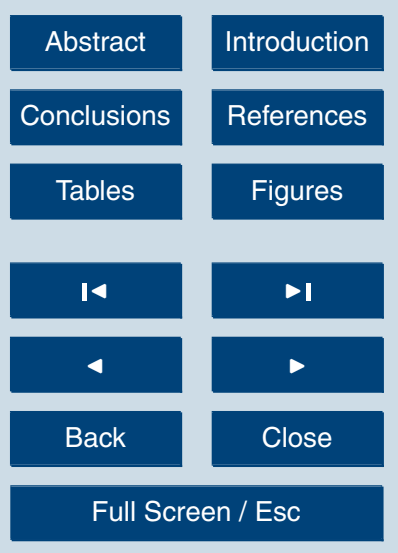

Printer-friendly Version

Interactive Discussion 
salinity dominant term (1-6)

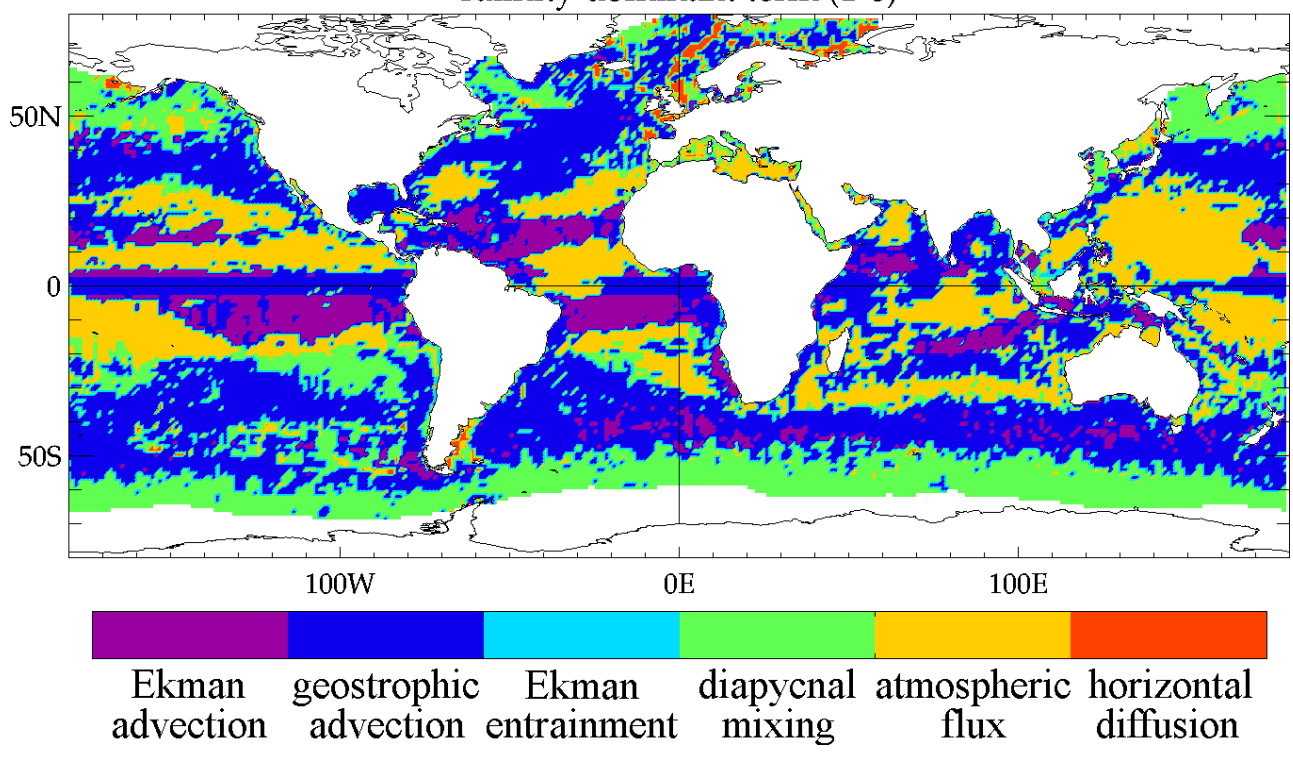

Fig. 11. Dominant term of the mixed layer salinity balance from the simulation. Areas temporarily covered with sea-ice are excluded, as their mean amplitudes are not representative of the annual balance. (See the text for the computation details.)
SSS variability from a global MLM

\section{S. Michel et al.}

\section{Title Page}

\section{Abstract}

Introduction

Conclusions

References

Tables

Figures
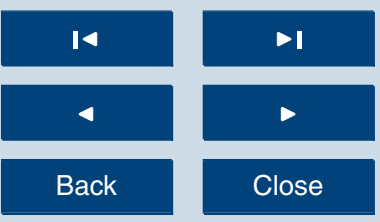

Full Screen / Esc

Printer-friendly Version

Interactive Discussion 


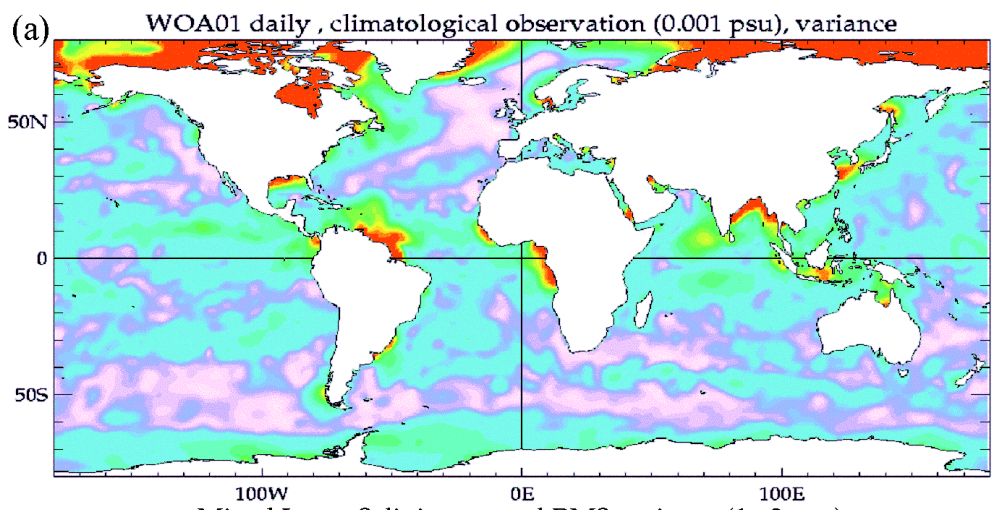

OSD

(b)

Mixed Layer Salinity, annual RMS variance (1e-3 psu)

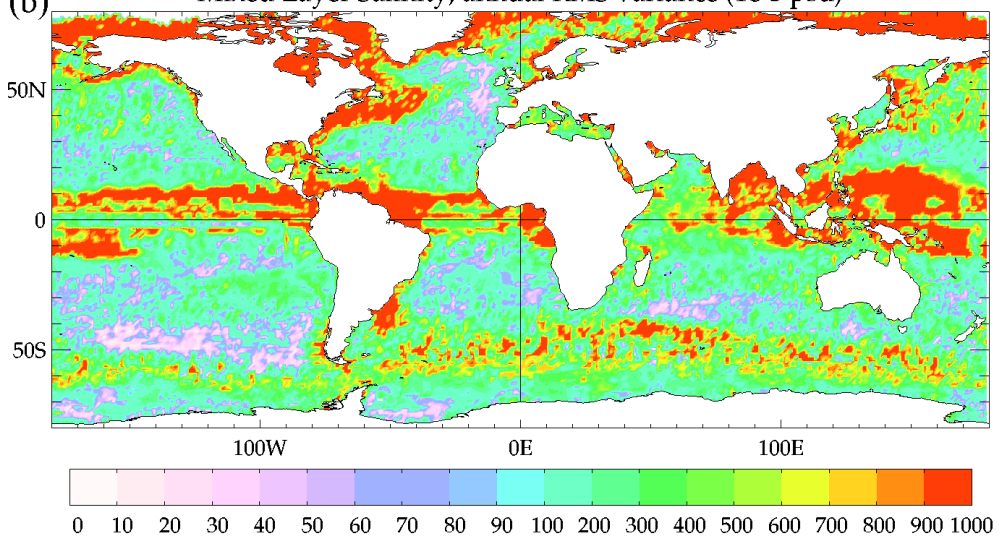

4, 41-106, 2007

SSS variability from a global MLM

S. Michel et al.

Title Page

Abstract

Introduction

Conclusions

References

Tables

Figures

14

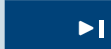

4

Back

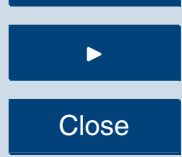

Full Screen / Esc

Printer-friendly Version

Interactive Discussion

EGU 
total variation ( $1 \mathrm{e}-3 \mathrm{psu} /$ day), annual RMS variance

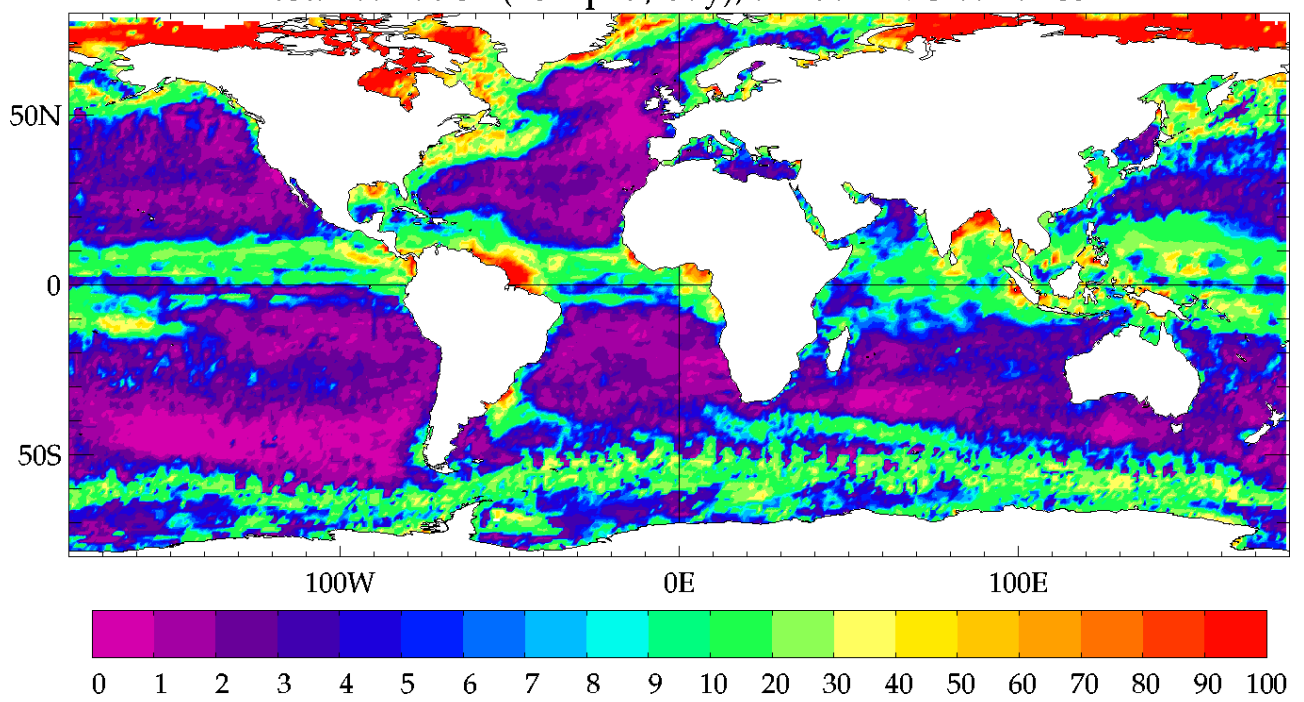

Fig. 13. Standard deviation of the salinity daily increments (in $10^{-3} \mathrm{psu}$ ), as defined in Eq. (7), from the simulation. The colour scale is non-linear, with intervals of 1 for $0<\sigma_{d}<10$ and 10 for $10<\sigma_{d}<100$.
SSS variability from a global MLM

S. Michel et al.

\section{Title Page}

\section{Abstract}

Introduction

Conclusions

References

Tables

Figures

14

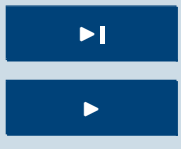

Back

Close

Full Screen / Esc

Printer-friendly Version

Interactive Discussion 


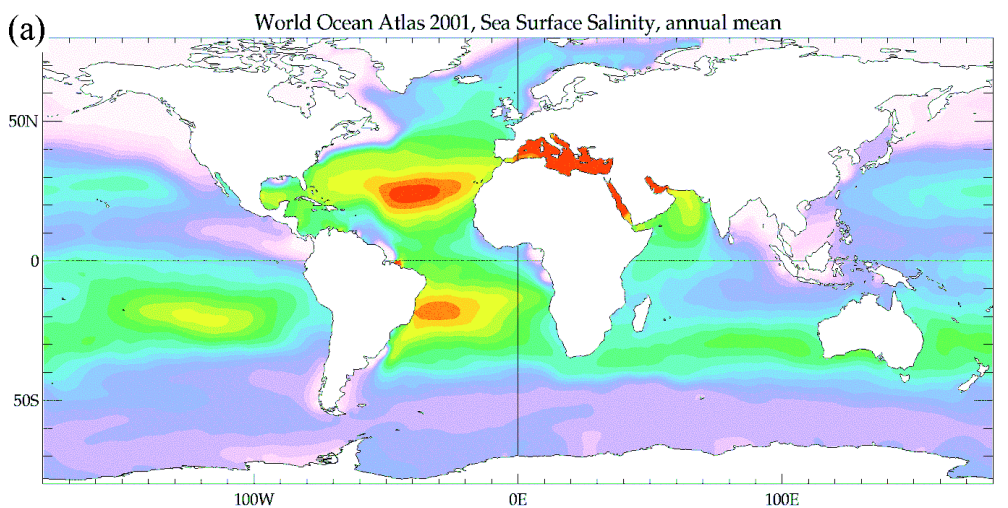

OSD

4, 41-106, 2007

SSS variability from a global MLM

S. Michel et al.

Title Page

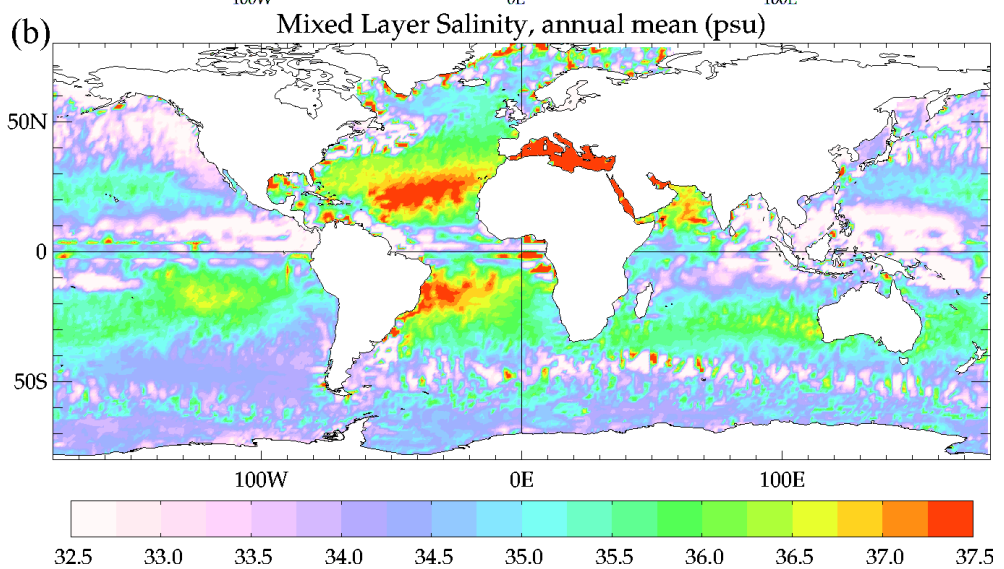

Full Screen / Esc

Fig. 14. Annual mean of the surface salinity (in psu) from (a) the World Ocean Atlas 2001

Interactive Discussion climatology and (b) the simulation. The colour scale is linear, with intervals of 0.25 psu. 